\title{
Article \\ Endopolyploidy Variation in Wild Barley Seeds across Environmental Gradients in Israel
}

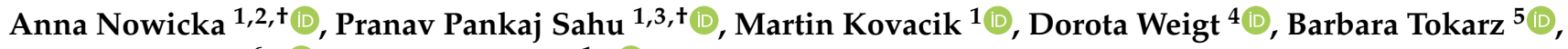 \\ Tamar Krugman 6,*(D) and Ales Pecinka 1,*(D)
}

check for

updates

Citation: Nowicka, A.; Sahu, P.P.; Kovacik, M.; Weigt, D.; Tokarz, B.;

Krugman, T.; Pecinka, A.

Endopolyploidy Variation in Wild

Barley Seeds across Environmental

Gradients in Israel. Genes 2021, 12,

711. https://doi.org/10.3390/

genes12050711

Academic Editors: Elwira Sliwinska,

Monika Rewers and Iwona

Jedrzejczyk

Received: 16 March 2021

Accepted: 7 May 2021

Published: 10 May 2021

Publisher's Note: MDPI stays neutral with regard to jurisdictional claims in published maps and institutional affiliations.

Copyright: (c) 2021 by the authors. Licensee MDPI, Basel, Switzerland. This article is an open access article distributed under the terms and conditions of the Creative Commons Attribution (CC BY) license (https:// creativecommons.org/licenses/by/ $4.0 /)$.
1 Centre of the Region Haná for Biotechnological and Agricultural Research, Institute of Experimental Botany, Czech Academy of Sciences, Šlechtitelů 31, 77900 Olomouc, Czech Republic; nowicka@ueb.cas.cz (A.N.); sahu@ueb.cas.cz (P.P.S.); kovacik@ueb.cas.cz (M.K.)

2 The Franciszek Górski Institute of Plant Physiology, The Polish Academy of Sciences, Niezapominajek 21, 30-239 Krakow, Poland

3 Global Change Research Institute of the Czech Academy of Sciences, Bělidla 986/4a, 60300 Brno, Czech Republic

4 Department of Genetics and Plant Breeding, Poznan University of Life Sciences, 11 Dojazd St., 60-632 Poznan, Poland; dorota.weigt@up.poznan.pl

5 Department of Botany, Physiology and Plant Protection, Faculty of Biotechnology and Horticulture, University of Agriculture in Krakow, Al. 29 Listopada 54, 31-425 Krakow, Poland; barbara.tokarz@urk.edu.pl

6 Institute of Evolution, University of Haifa, Abba Khoushy Ave. 199, Haifa 3498838, Israel

* Correspondence: tkrugman@evo.haifa.ac.il (T.K.); pecinka@ueb.cas.cz (A.P.); Tel.: +972-4-8240783 (T.K.); +420-585-238-709 (A.P.)

+ These authors contributed equally to this work.

Abstract: Wild barley is abundant, occupying large diversity of sites, ranging from the northern mesic Mediterranean meadows to the southern xeric deserts in Israel. This is also reflected in its wide phenotypic heterogeneity. We investigated the dynamics of DNA content changes in seed tissues in ten wild barley accessions that originated from an environmental gradient in Israel. The flow cytometric measurements were done from the time shortly after pollination up to the dry seeds. We show variation in mitotic cell cycle and endoreduplication dynamics in both diploid seed tissues (represented by seed maternal tissues and embryo) and in the triploid endosperm. We found that wild barley accessions collected at harsher xeric environmental conditions produce higher proportion of endoreduplicated nuclei in endosperm tissues. Also, a comparison of wild and cultivated barley strains revealed a higher endopolyploidy level in the endosperm of wild barley, that is accompanied by temporal changes in the timing of the major developmental phases. In summary, we present a new direction of research focusing on connecting spatiotemporal patterns of endoreduplication in barley seeds and possibly buffering for stress conditions.

Keywords: Endoreduplication; endosperm; Hordeum vulgare ubsp. spontaneum; seed development; super cycle value

\section{Introduction}

Cultivated barley (Hordeum vulgare subsp. vulgare, $2 \mathrm{n}=2 \mathrm{x}=14$ ) was domesticated about 10,000 years ago from its progenitor wild barley (H. vulgare subsp. spontaneum, $2 n=2 x=14$ ). Barley belongs to the group of "Neolithic founder crops", and was one of the first cereals that became a pillar of food and feed for ancient societies [1]. The Fertile Crescent is the center of barley domestication, distribution, and diversity [1]. A recent archegenomic study performed on ancient DNA of 6000 years-old barley grains excavated at a cave in the Judean Desert in Israel, narrowed its domestication region to the Upper Jordan Valley [2]. Subspecies spontaneum is distributed from eastern North Africa, through the Middle East to India and west China [1]. It constitutes an important annual element of open herbaceous and park-like vegetation [3]. Wild barley natural habitats are 
characterized by wide ecogeographical diversity caused mostly by contrasting climatic and topographic conditions within the East Mediterranean region. This is reflected by its phenotypic and genetic heterogeneity [4]. During the last century, wild barley was collected all over its distribution area and seed samples are stored and maintained in ex situ gene-banks $[3,4]$. While domestication and modern plant breeding have reduced the genetic diversity of cultivated barleys, the stocks of subsp. spontaneum form a major source for variability, novel genes, and alleles for barley breeding [5,6]. For example, wild barley was found to be an important source of resistance to biotic and abiotic stresses, including multiple diseases [7], tolerance to cold [8], drought [9], and salt [10].

Cereal grain development includes three major phases, characterized by different cellular and physiological events (Figure 6a-c quoted from [11]). Phase I starts with double fertilization and passes smoothly into the cells/nuclei proliferation; phase II comprises differentiation of embryo and endosperm tissues, and seed mass gain by the accumulation of storage compounds; phase III corresponds to seed maturation, weight reduction by desiccation, and an onset of dormancy. These phases partially overlap with three morphological caryopsis growth stages named water, milk, and dough, respectively [12].

Cereal grain consists of three major compartments: multilayered seed maternal tissues (SMTs; nucellar projection, pericarp plus seed coats), endosperm, and embryo. The pericarp (diploid, 2x) is derived from the ovary wall and adheres strongly to the seed coats of the ovule [13]. Within the first days after pollination (DAP), the pericarp serves to protect and support the growing endosperm and embryo by starch deposition and photosynthesis in cultivated barley $[14,15]$. During double fertilization, one sperm nucleus fuses with the egg cell nucleus and gives rise to the diploid embryo $(2 \mathrm{x})$, while the second sperm cell nucleus fuses with the diploid central cell to form a triploid endosperm (3x) with the peculiar genetic constitution of one paternal and two maternal genomes. Endosperm nuclei first form syncytium (a.k.a. coenocyte) and later endosperm cellularizes and differentiates into five specialized tissues: the central starchy endosperm (CSE), the sub-aleurone layer (SAL), the aleurone layer (AL), the basal endosperm transfer layer (BETL), and the embryosurrounding region (ERS) [16]. Endosperm protects and nourishes the embryo. It is the main caryopsis part accumulating primarily sugars and proteins $[13,16]$. The cereal kernel is covered by hulls that consist of the lemma, palea, and glumes of maternal origin and which remain tightly attached to the grain even after ripening [17].

Both SMTs and endosperm tissues undergo genetically controlled endoreduplication during seed development in cultivated barley [11]. Endoreduplication (a.k.a. endopolyploidization) occurs via the endocycle and is a variant of the cell cycle, in which cell nuclei increase their ploidy through repeated rounds of replication without cell divisions (reviewed, e.g., in $[18,19])$. To unravel the mechanism involved in the switch from a mitotic cell cycle to an endocycle many cyclin-dependent kinases (CDKs), their cyclin partners, CDK inhibitors (e.g., WEE1), and retinoblastoma-related (RBR) proteins have been studied [20]. Despite many efforts, the knowledge about the molecular control of endoreduplication is fragmentary. In most Angiosperms, endoreduplication is common in specialized cells producing secondary metabolites and/or as a means to accelerate cell expansion of specific tissues [20]. Also, various abiotic and biotic factors affect the endopolyploidy level of cells and tissues [21,22]. For instance, salinity or the absence of light stimulates extra endocycles in different Arabidopsis organs [23,24]. Endoreduplication can also be triggered upon symbiotic [25] and also pathogenic [26] plant-microbe interactions. In contrast, endopolyploidization can be repressed by both very high and very low temperatures [22] or drought [27].

The development of cereal seeds would not be possible without programmed cell death (PCD). In phase I, maternal tissues, i.e., components of the embryo sac, nucellus, nucellar projection, seed coats, and pericarp undergo a progressive degeneration by PCD [28,29]. During phases II and III, mainly two endosperm parts: ESR and CSE undergo cell death, but the cells remain intact in the mature grain and their contents will not be 
remobilized until germination. Finally, the mature grain contains mainly dead material, where only the embryo, BETL, and AL tissues remain alive [30-32].

Wild barley is a generalist abundant across diverse habitats ranging from the mesic Mediterranean meadows to the xeric southern habitats and even penetrating the central Negev desert in Israel. Such environmental heterogeneity can be a direct driving force for adaptation [4]. The main objective of this study was to investigate the dynamics of endoreduplication in seed tissues of wild barley originating from mesic, semi-mesic, semixeric, and xeric ecogeographic sites of Israel. For this purpose, we measured the DNA contents in diploid seed tissues (embryo and maternal tissues) and triploid endosperm using flow cytometry. We calculated the proportion of nuclei with different DNA contents and estimated the level of endoreduplication with a new formula called the super cycle value (SCV) [11]. For a better understanding of the dynamics of processes associated with wild barley grain development, we also monitored the morphology of developing seeds and performed Evans blue cell death assay. We found that wild barley accessions originating from the xeric environments have on average higher proportion of endoreduplicated nuclei in seed tissues, and tend to have a higher SCV index. This indicates the impact of harsh conditions on endoplyploidization. A comparison of wild and cultivated barleys reveals a higher endopolyploidy level in the endosperm of wild barley that is accompanied by temporal changes in the timing of the major developmental phases.

\section{Materials and Methods}

\subsection{Plant Materials and Growth Conditions}

Ten wild barley (H. vulgare subsp. spontaneum) accessions originating from Israel were used in this study. Seeds were obtained from the Institute of Evolution Wild Cereal Gene Bank (ICGB) at the University of Haifa, Israel, and Leibniz Institute of Plant Genetics and Crop Plant Research (IPK), Gatersleben, Germany. The ICGB accessions were named based on the seed collection sites and the type of environment (Figure 1; Table 1). Three accessions originated from typical xeric (x) environments: Machtesh Gadol (MGx), Mehola (MHx), and Wadi Qilt (WQx); three from mesic (m) environments: Rosh Pinna (RPm), Tel Hai (THm), and Zefat (ZFm), and one accession from Bar Giyyora represented semi-mesic environment (BGsm). Two accessions originated from Nahal Oren (NO) Canyon, also named "Evolution Canyon" [32]. The first NO accession was collected from the Northfacing slope (NFS) representing a mesic environment (NOm), and the second from the South-facing slope (SFS) belonging to the semi-xeric group (NOsx). In brief, the xeric environment is characterized by low annual rainfall and high temperatures, and mesic by high annual rainfall and lower temperatures. Differences between environments are mainly reflected at seed development time during March to April. The environmental conditions at BG are regarded as semi-mesic due to the high rainfall and dry environment in the Judean mountains. The SFS is regarded as semi-xeric due to higher solar radiation as compared with the NFS Nahal Oren. The IPK accession HS584 carries the gene bank name HOR 12560, and the exact site of the collection is unknown.

Also, published data [11] from six cultivars (cv.) of two-rowed spring barley (H. vulgare subsp. vulgare): Betzes (PI 129430), Compana (PI 539111), Golden Promise (GP; PI 343079), Ingrid (PI 263574), Klages (CIho 15478) and Mars (PI 599629) and three additional cv. of six-rowed spring barley: Glacier (CIho 6976), Mars (CIho 7015) and Morex (BCC 906) were used for comparison.

Grains were stratified in the dark at $4{ }^{\circ} \mathrm{C}$ for $48 \mathrm{~h}$, evenly spread on wet filter paper in a Petri dish, covered with a lid, and germinated at $25^{\circ} \mathrm{C}$ for 3 days in the dark. Germinating kernels were planted into $5 \mathrm{~cm} \times 5 \mathrm{~cm}$ peat pots with a mixture of soil and sand (2:1, $v / v$ ) and grown in an air-conditioned phytochamber with a long day regime (16 h day with $20^{\circ} \mathrm{C}$ and $200 \mu \mathrm{mol} \mathrm{m}{ }^{-2} \mathrm{~s}^{-1}$ light intensity; $8 \mathrm{~h}$ night with $16^{\circ} \mathrm{C} ; 60 \%$ humidity). After 10 days, wild barley plants were placed into the vernalization chamber (short-day regime; $8 \mathrm{~h}$ day with $4{ }^{\circ} \mathrm{C}$, light intensity $200 \mu \mathrm{mol} \mathrm{m}{ }^{-2} \mathrm{~s}^{-1}$; $16 \mathrm{~h}$ night with $4{ }^{\circ} \mathrm{C}$; humidity $85 \%$ ) for three weeks. Ten-day-old cultivated barley plants and 31-day-old wild barley 
plants were transferred into the $12 \mathrm{~cm} \times 12 \mathrm{~cm}$ pots filled with the above-described soil mixture and grown under long-day conditions. For each accession five plants were grown. Day of pollination (DOP) was monitored using the morphology of stigma and anthers according to the Waddington scale (W10) [33] as we described previously [11,34]. In brief, the spikelets at DOP were characterized by extended hulls, widely branched stigma, and the presence of pollen grains on stigmatic hairs. Seeds were collected from the center of the spikelet at two- and four-day intervals, starting from 4 until 24 days after pollination (DAP). For this experimental setup, in total seven-time points were examined (i.e., 4, 6, $8,12,16,20,24$ DAP). For three accessions, HS584, RPm, and BGsm collecting the seeds were extended up to $48 \mathrm{DAP}$ (additional six collection points: 28, 32, 36, 40, 44, 48 DAP). Mature dry seeds (called 'dry seeds' latter in the text) were harvested around 60-65 DAP from fully dried mother plants, cleaned, and stored first $\sim 30$ days at $20^{\circ} \mathrm{C}$, then $\sim 60$ days at $4{ }^{\circ} \mathrm{C}$, both in darkness. The analysis was performed after $90 \pm 5$ days after harvesting the seeds. During collecting the seed from mother plants, kernels were at the hard-dough phase of barley grain development (87-89 stages according to [12]). It means that grains were dry and cannot be squeezed out. The maximum dry seed section area was reduced by approximately $30-40 \%$ as compared to $20-28$ DAP seeds (Supplementary Figure S5). Hulls had yellow color.

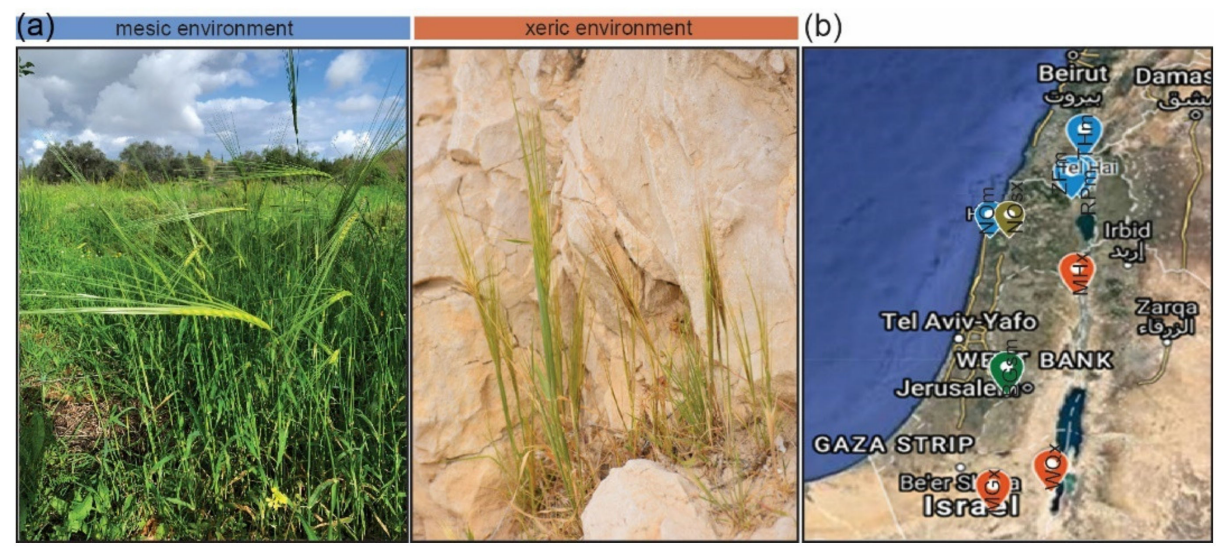

Figure 1. Geographic origin of wild barley (H. vulgare subsp. spontaneum) accessions. (a) Examples of wild barley from the Galilee (mesic) and Judean desert (xeric) in Israel. (b) Collection sites in Israel. Blue points $=$ mesic sites $(\mathrm{THm}=$ Tel Hai, ZFm $=$ Zefat, RPm $=$ Rosh Pinna, NOm = Nahal Oren northern facing slope); green point = semi-mesic site (BGsm = Bar Giyyora); green-brown point = semi-xeric site $($ NOsx $=$ Nahal Oren southern facing slope); orange points = xeric sites $(\mathrm{MHx}=$ Mehola, $\mathrm{MGx}=$ Machtesh Gadol, WQx = Wadi Qilt). The map was generated using Google Maps. Detailed ecogeographical data are presented in Table 1. 
Table 1. Sampling sites and ecogeographical data of the analyzed wild barley accessions.

\begin{tabular}{|c|c|c|c|c|c|c|c|c|c|c|c|c|}
\hline $\begin{array}{l}\text { Locality/Name } \\
\text { (All within Israel) }\end{array}$ & Genebank & Acronym & $\begin{array}{c}\text { Type of } \\
\text { Environment }\end{array}$ & Longitude (N) & Latitude (E) & $\underset{\text { (a.s.1.) }}{\text { Altitude }}$ & $\begin{array}{l}\text { Maximum } \\
\text { Temperature } \\
\text { in April }\left({ }^{\circ} \mathrm{C}\right)\end{array}$ & $\begin{array}{l}\text { Rainfall in } \\
\text { April (mm) }\end{array}$ & $\begin{array}{c}\text { Annual } \\
\text { Rainfall (mm) }\end{array}$ & $\begin{array}{c}\text { Average Annual } \\
\text { Humidity at 14:00 } \\
\text { Mean } \pm \text { SD }\end{array}$ & $\underset{\text { Annual }}{\text { Anaporation (cm) }}$ & Soil Type \\
\hline Bar Giyyora & ICGB & BGsm & Semi-mesic & 35.083333 & 31.716667 & 760 & 22 & 18 & 535 & $47.1 \pm 10.8$ & 215 & $\mathrm{~T}$ \\
\hline HS584 & IPK & HS584 & n.a. & n.a. & n.a. & n.a. & n.a. & n.a. & n.a. & n.a. & n.a. & n.a. \\
\hline Machtesh Gadol & ICGB & MGx & Xeric & 35.000000 & 30.950000 & n.a. & 25 & 3 & 70 & n.a. & n.a. & n.a. \\
\hline Mehola & ICGB & MHx & Xeric & 35.533333 & 32.350000 & -150 & 30 & 6 & $<200$ & 37.5 & 240 & $\mathrm{~A}$ \\
\hline Nahal Oren & ICGB & $\mathrm{NOm}$ & Mesic & 34.966667 & 32.716667 & n. a. & 24 & 13 & 584 & n.a. & n.a. & n.a. \\
\hline Nahal Oren & ICGB & NOsx & Semi- xeric & 34.966667 & 32.716667 & n. a. & 24 & 13 & 584 & n.a. & n.a. & n.a. \\
\hline Tel Hai & ICGB & THm & Mesic & 35.573979 & 33.234719 & 400 & 26 & 23 & 768 & $46.9 \pm 7.6$ & 220 & $\mathrm{~T}$ \\
\hline Wadi Qilt & ICGB & WQx & Xeric & 35.44565 & 31.859 & 50 & 30 & 6 & $<200$ & $34.7 \pm 9.3$ & 330 & $\mathrm{~A}$ \\
\hline Zefat & ICGB & $\mathrm{ZFm}$ & Mesic & 35.496001 & 32.969206 & 800 & 20 & 27 & 670 & $50.4 \pm 13.1$ & 220 & $\mathrm{R}$ \\
\hline
\end{tabular}

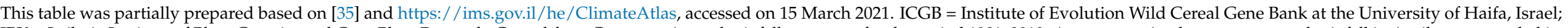

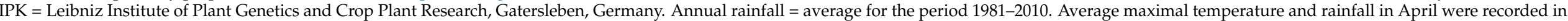
1995-2009. a.s.l.—above sea level; n.a.—not available; SD—standard deviation over mean monthly data; Soil type: $A=$ alluvium, $\mathrm{R}=$ rendzina, $\mathrm{T}=$ terra rossa. 


\subsection{Analysis of Nuclear DNA Content and Calculation of the Super Cycle Value (SCV)}

Nuclear DNA contents were estimated using flow cytometry (FCM). For each time point, five to six individual seeds, freshly collected from one spike were analyzed. The measurements were repeated three times on different days using seeds harvested from different mother plants and keeping the same time of day for analysis. The isolation of nuclei and estimation of nuclear DNA content was performed as previously described [11]. Briefly, seeds directly after harvesting were cleaned by removing hulls using tweezers. Then, single seeds were immediately homogenized with a razor blade in a Petri dish containing $500 \mu \mathrm{L}$ of Otto I solution ( $0.1 \mathrm{M}$ citric acid, $0.5 \%$ Tween 20$)$. The crude suspension was filtered through $50 \mu \mathrm{m}$ nylon mesh (Sysmex-Partec) and stained around $15 \mathrm{~min}$ with 1 $\mathrm{mL}$ of Otto II solution $\left(0.4 \mathrm{M} \mathrm{Na}_{2} \mathrm{HPO}_{4} \cdot 12 \mathrm{H}_{2} \mathrm{O}\right)$ supplemented with $2 \mu \mathrm{g} \mathrm{mL}^{-1}$ DAPI $\left(4^{\prime}, 6-\right.$ diamidino-2-phenylindole). Nuclei samples were analyzed using either a CyFlow Space or a Partec PAS I flow cytometers (Sysmex-Partec, Muenster, Germany), both equipped with UV-led diode lamps. For calibration of the cytometers, the optics were adjusted using calibration beads (A7304, Invitrogen, Carlsbad, CA, USA) until the coefficient of variation $(\mathrm{CV})$ reached $<2 \%$. At least 5000 particles were acquired per sample, using a $\log 3$ scale. Histograms were evaluated by the FloMax software (Sysmex-Partec, Muenster, Germany).

To estimate amount of endoreduplication, we used super cycle value (SCV) [11]. In SCV, $8 \mathrm{C}$ in the diploid and $12 \mathrm{C}$ in the triploid tissues were considered as the first levels of endopolyploid nuclei. Our rationale is, that it is not possible to unambiguously distinguish by FCM whether a given $4 \mathrm{C}$ (or $6 \mathrm{C}$ nucleus in endosperm) nucleus just entered endoreduplication or will mitotically divide [36]. For diploid tissues SCV $=((\mathrm{n} 2 \mathrm{C} \times 0)$ $+(\mathrm{n} 4 \mathrm{C} \times 0)+(\mathrm{n} 8 \mathrm{C} \times 1)+(\mathrm{n} 16 \mathrm{C} \times 2)) /(\mathrm{n} 2 \mathrm{C}+\mathrm{n} 4 \mathrm{C}+\mathrm{n} 8 \mathrm{C}+\mathrm{n} 16 \mathrm{C})$, and for triploid endosperm SCV $=((n 3 C \times 0)+(n 6 C \times 0)+(n 12 C \times 1)+(n 24 C \times 2)) /(n 3 C+n 6 C+n$ $12 C+n 24 C), n=$ number of counts per given $C$-value content.

\subsection{Determination of Seed Morphology Parameters}

Analysis of dry seed morphology parameters was performed in three biological replicates, each with at least 20 seeds collected from four to five spikes of different plants. Dry kernels were peeled off, weighed with an analytical scale (Sartorius, Göttingen, Germany), and photographed using a SZX16 binocular microscope (Olympus, Tokyo, Japan) bonded with a Regita 1300 QImaging camera and QCapture $\times 64$ software (Olympus). Seed length and width were measured using ImageJ calibrated with internal size control. Seeds from 4 to $48 \mathrm{DAP}$ and dry seeds were peeled off and cut with a razor blade along the longitudinal and transverse axis. At least 20 individual seeds were photographed as described above using a binocular microscope. Hulled seeds that possessed awns were photographed with a D5600 (Nikon, Tokyo, Japan) digital camera equipped with an $80 \mathrm{~mm}$ Nikkor objective. All photo-matrix were composed of separately taken photos of individual seeds and merged in Adobe Photoshop CS5 (Adobe Inc., San Jose, CA, USA).

\subsection{Cell Death Assay by Evans Blue Staining}

Seeds from 4 to 48 DAP and dry seeds were peeled off and cut with a razor blade along the longitudinal and transverse axis. At least 20 individual seeds bulked from four to five spikes of different plants were stained in $0.1 \%(w / v)$ Evans blue (314-13-6, SigmaAldrich, St. Louis, MO, USA) for $2 \mathrm{~min}$. Stained sections were washed twice for $10 \mathrm{~min}$ with distilled water [31]. Transverse and sagittal sections of samples were analyzed with an SZX16 binocular microscope (Olympus). Images were captured with a Regita 1300 QImaging camera and QCapture $\times 64$ software (Olympus) using the same settings and proceeded in Adobe Photoshop CS5 (Adobe Inc.).

\subsection{Statistical Analysis}

All data after testing for normal distribution were examined by one- or two-way analysis of variance (ANOVA), after which post hoc comparison was performed using 
Duncan's multiple ranges $(p \leq 0.05)$ test. Data expressed as percentages were first transformed using arcsine transformation. Principal component (PC) analysis was used to analyze relations between variables. Statistical analyses were performed in Statistica v. 12 (Stat Soft Inc., Tulsa, OK, USA), Minitab v. 18 (Minitab, LLC, State College, PA, USA) or RStudio programs.

\section{Results}

\subsection{Variation in Mature Dry Seed Morphology of Wild Barley}

We used samples from nine geographically distant sites from North to South Israel along with the aridity gradient (Figure 1b; Table 1). Also, we included a commonly used gene-bank accession of wild barley named HS584 from an unknown origin in Israel. The wild barley accessions varied as to their mature dry seed weight, length, width, and awn length (Figure 2a-d; Supplementary Figure S1). For example, the TKW in wild barleys ranged from $14.2 \mathrm{~g}$ (MHx) to $40.5 \mathrm{~g}$ (NOm). We noted that seeds of wild barley were longer than those of cultivars (wild barley seed length $\geq 9 \mathrm{~mm}$, cultivars seed length $\sim 7-8 \mathrm{~mm}$ ) (Supplementary Figure S1a). However, only slight differences between wild barleys appeared for seed width (Supplementary Figure S1b). Seeds of wild barley accessions had longer awn. We also noted an intraspecific variation with xeric accessions having shorter awns than the mesic ones (Supplementary Figure S1c). ANOVA results showed that the values of observed variables between wild barley depended on the accession (genotype), and except for seed length, also from the type of environment (Figure 2d). Using these seed phenotypic data, we performed principal component (PC) analysis (Figure 2c; Supplementary Figure S2). However, this analysis did not reveal any specific group. We noted that one xeric accession MHx varied from the rest of the wild barleys. In addition, barley cultivars were separated from wild accessions.

Collectively, these data show a phenotypic variation of wild barley seeds. The shortened seed awn length is the most pronounced feature differentiating xeric barley accessions.

\subsection{Variation in Endoreduplication Dynamics in Developing Wild Barley Seeds}

\subsubsection{Diploid Seed Tissues}

We used whole peeled seeds (hulls were manually removed) to study the degree of endopolyploidy in the seeds of wild barley. We measured C-values of diploid nuclei from the embryo (EMB) and seed maternal tissues (SMTs, containing: nucellar projection, pericarp, and seed coats) and of triploid nuclei fraction represented by endosperm (END) (Supplementary Figure S3). These measurements were performed for a period 4-24 DAP and then in dry seeds (Results for endosperm are presented in the next subsection numbered 3.2.2.). Diploid seed tissues contained $2 \mathrm{C}$ and $4 \mathrm{C}$ nuclei representing G1 and G2 phases of the cell cycle, and $8 \mathrm{C}$ and $16 \mathrm{C}$ endoreduplicated nuclei originating from one and two endocycles, respectively (Supplementary Figure S3).

We found that all wild barleys contained similar amounts of $2 \mathrm{C}$ and $4 \mathrm{C}$ nuclei, each oscillating between $40 \%$ to $50 \%$, with a minimal amount $\leq 10 \%$ of endoreduplicated nuclei at $4 \mathrm{DAP}$. Up to $12 \mathrm{DAP}$ the number of endopolyploid nuclei increased to reach the maximum, i.e., $10-24 \%$ for $8 \mathrm{C}$ and $5-11 \%$ for $16 \mathrm{C}$. After $20 \mathrm{DAP}$, the $2 \mathrm{C}$ nuclei fraction increased, while the proportion of $4 \mathrm{C}, 8 \mathrm{C}$, and $16 \mathrm{C}$ was gradually reduced. Finally, in mature dry seeds, $2 \mathrm{C}$ nuclei amounted to around half $(50-60 \%), 4 \mathrm{C}$ nuclei around $30 \%$, and $8 \mathrm{C}$ and $16 \mathrm{C}$ nuclei $<20 \%$ (Figure 3a; Supplementary Tables S1). AVOVA results showed that the values of these variables depended on both the type of environment and DAP and the interaction between these two factors (Figure 3c). 


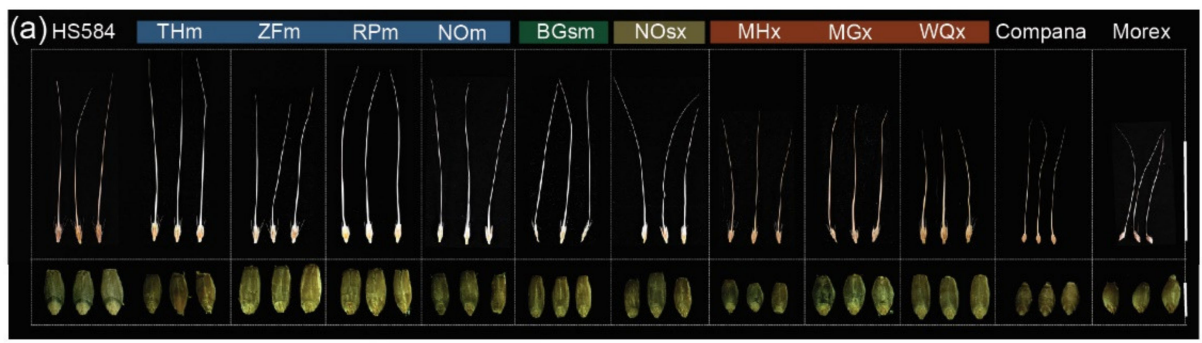

(b)

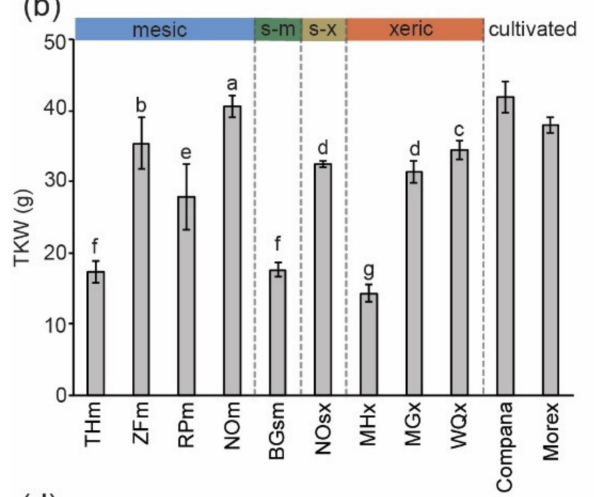

(c)

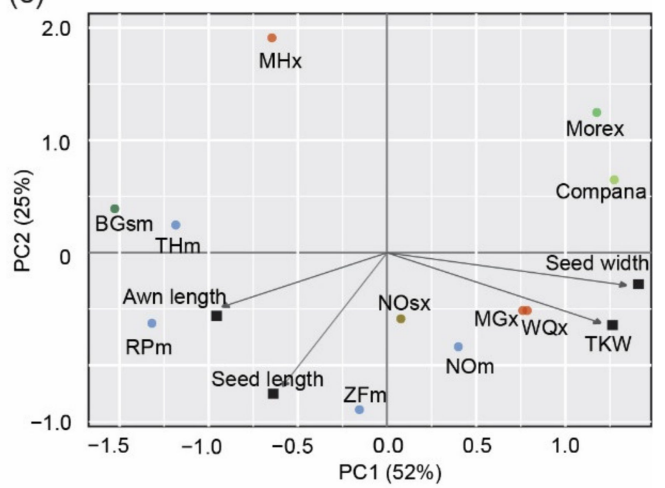

(d)

\begin{tabular}{|c|c|c|c|c|}
\hline Parameter & TKW & Seed length & Seed width & Awn length \\
\hline Source of variation & & Mean s & $\operatorname{ares} / p$ & \\
\hline Accession & $1530.674 / * \star \star *$ & $28.702 / * \star \star *$ & $1.011 / * \star \star *$ & $209.095 / * \star \star *$ \\
\hline Environment & 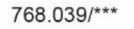 & $5.267 / \mathrm{ns}$ & $1.047 /^{\star * * *}$ & $223.176 / /^{\star \star \star}$ \\
\hline
\end{tabular}

Figure 2. Dry seed phenotypes of wild barley accessions. (a) Dorsal views of hulled dry seeds with awns (upper panel; Scale bar $=10 \mathrm{~cm}$ ) and peeled dry seeds (lower panel; scale bar $=10 \mathrm{~mm}$ ). Mesic accessions: THm = Tel Hai, ZFm = Zefat, RPm = Rosh Pinna, NOm = Nahal Oren NSF; semi-mesic accession: BGsm = Bar Giyyora; semi-xeric accession: NOsx = Nahal Oren SFS; xeric accessions: MHx = Mehola, MGx = Machtesh Gadol, WQx = Wadi Qilt. All genotypes were grown in phytochamber under the same conditions. (b) Quantitative data for the thousand-kernel weight (TKW). Data are the means $( \pm S D)$ from three biological replicates. Values marked with the same letter do not differ according to Duncan multiple range tests $(p \leq 0.05)$. (c) Principal component (PC) analysis of TKW, seed length, and width for peeled seeds, and awn length. The positions represent contribution rates of the two PCs (Source data are shown in Supplementary Figure S1, other combinations of PCs are presented in Supplementary Figure S2). The ecological conditions at the sampling site of HS584 are unknown. Compana and Morex represent two- and six-rowed cultivated barley controls, respectively. (d) Summary of ANOVA performed for seed traits. The sources of variance were as follows: nine accessions and four environment types. ${ }^{* *}$ Significant at $p \leq 0.001$; ns-not significant.

To estimate the degree of endoreduplication, we calculated the SCV parameter (Figure 3b; Supplementary Table S2). At 4 DAP, a very low SCV of $\leq 0.09$ was observed for all accessions. From 6 DAP onwards, the SCV increased to reach the peak at 12-24 DAP depending on the genotype. The highest SCV of 0.42 , appeared in the two xeric accessions MGx and WQx, at 16 and 24 DAP, respectively. Both accessions originate from the most southern collection sites (Figure 1). Similar to the previous observation, the values of these variables depended on the environment type and DAP, as well as the interaction between these two components (Figure 3c). The SCV curve for HS584 had a very smooth profile without any abrupt changes between neighborhood time points, and resembled the THm SCV line (Figure 3b).

Taken together, these data show endoreduplication variation in developing embryos and/or SMTs of wild barley seeds. The most southern xeric accessions show a tendency for a higher endopolyploidy level. 
(a)

$\mathrm{EMB}+\mathrm{SMTS}$
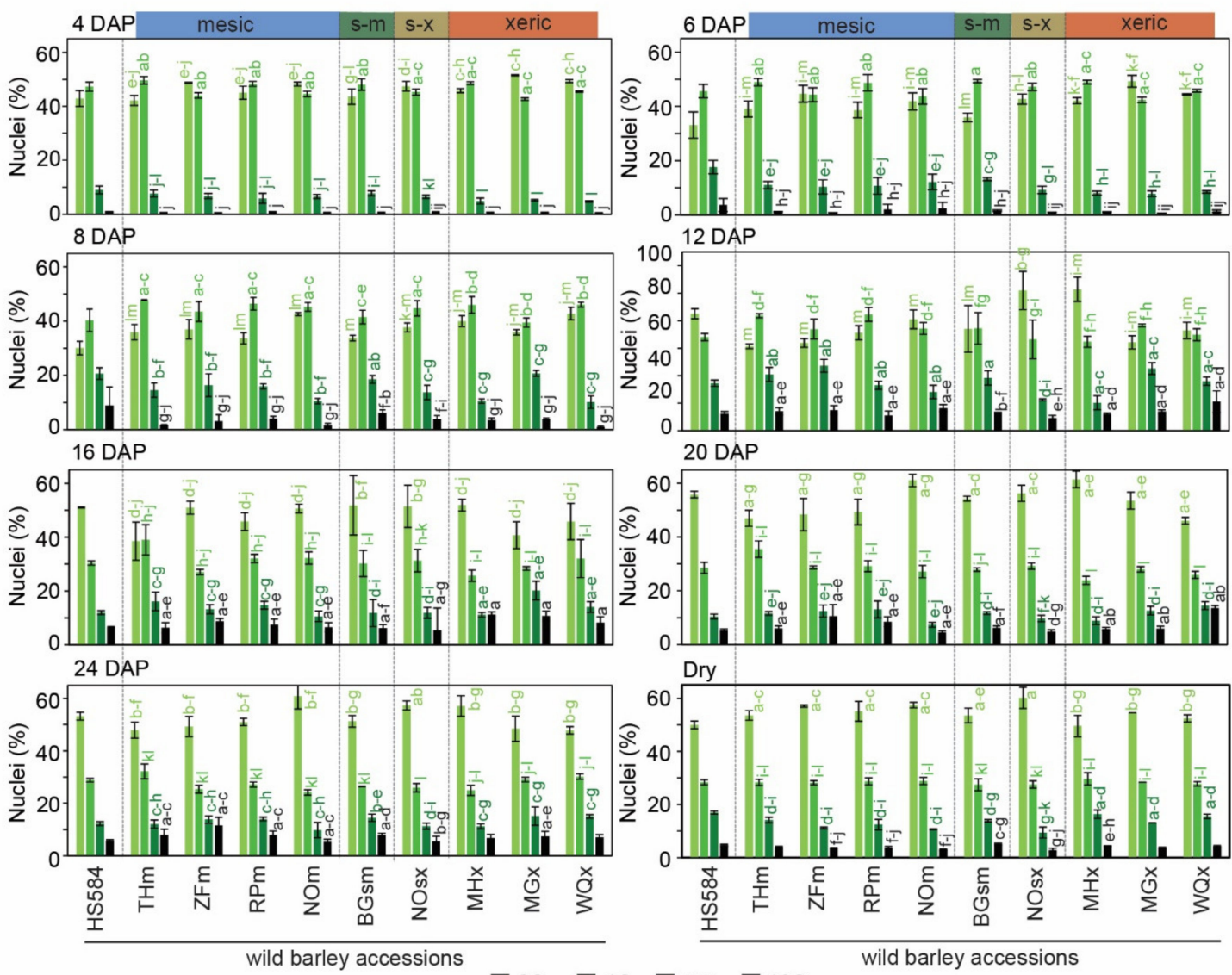

(b)

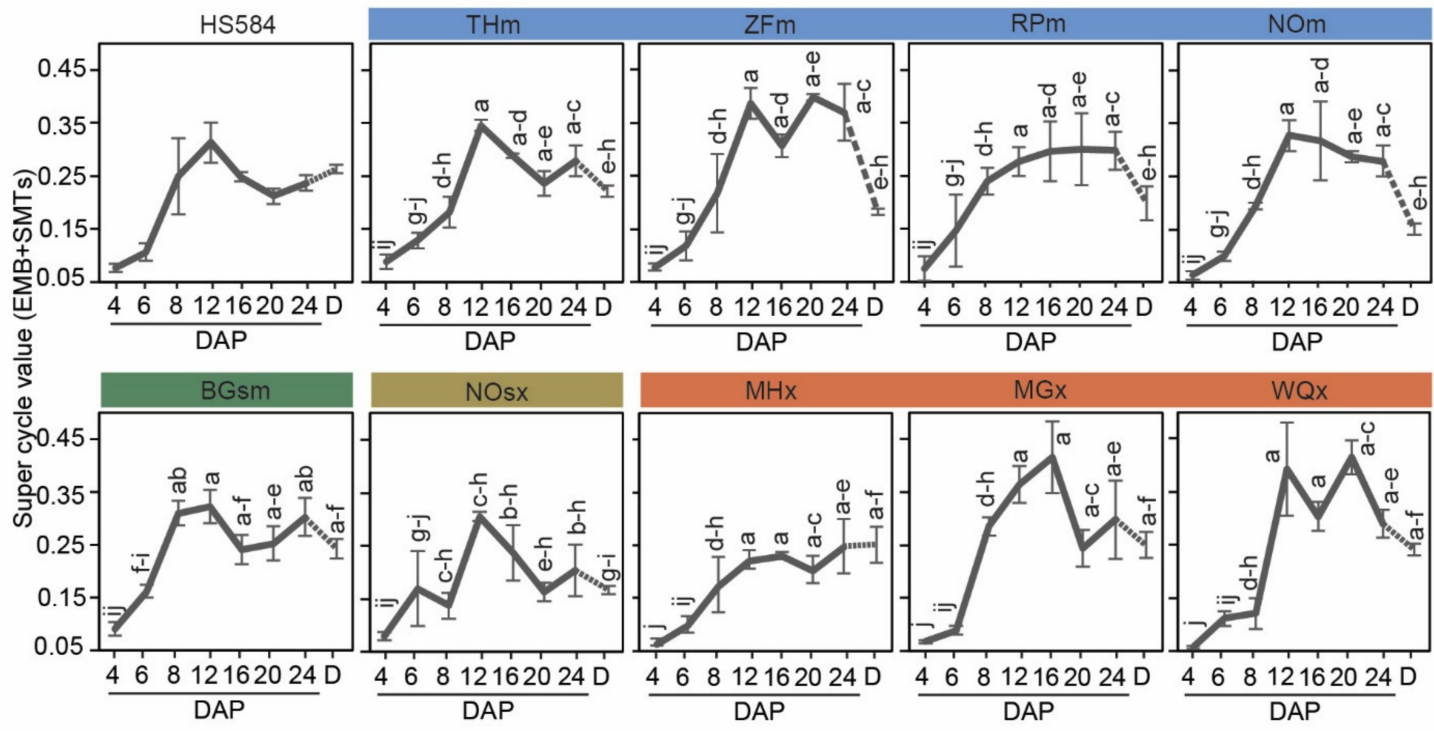

(c)

\begin{tabular}{|c|c|c|c|c|c|}
\hline Parameter & $2 \mathrm{C}(\%)$ & $4 \mathrm{C}(\%)$ & $8 \mathrm{C}(\%)$ & $16 \mathrm{C}(\%)$ & SCV \\
\hline Source of variation & & Mean square & & & \\
\hline Environment & $172.190 / * * *$ & $51.4811^{*}$ & 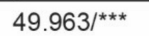 & $16.912 /^{*}$ & 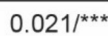 \\
\hline DAP & 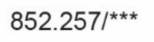 & $1392.184^{/ * \star *}$ & $176.177 / * * *$ & 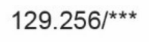 & $0.106 / * \star \star x$ \\
\hline Environment $\times$ DAP & $47.693 /^{*}$ & $13.205 / \mathrm{ns}$ & $15.844 /^{\star}$ & $7.029 /^{\star}$ & $0.006 /{ }^{*}$ \\
\hline
\end{tabular}

Figure 3. Estimation of C-values in diploid seed tissues represented by the embryo (EMB) and seed maternal tissues (SMTs) of ten wild barley accessions originating from Israel. (a) Percentage of $2 \mathrm{C}, 4 \mathrm{C}, 8 \mathrm{C}$ and $16 \mathrm{C}$ nuclei at a given day after pollination 
(DAP) and in dry seeds. Mesic accessions: THm = Tel Hai, ZFm = Zefat, RPm = Rosh Pinna, NOm = Nahal Oren NSF; semi-mesic accession: BGsm = Bar Giyyora; semi-xeric accession: NOsx = Nahal Oren SFS; xeric accessions: MHx = Mehola, MGx = Machtesh Gadol, WQx = Wadi Qilt. The ecological conditions at the sampling site of HS584 are unknown. Data are the means $( \pm S D)$ from three biological replicates, each with at least 5 individual measurements (seeds). Data marked with the same letter do not differ according to the Duncan test $(p \leq 0.05)$ (Source data are shown in Supplementary Table S1 (b) Super cycle values at a given DAP calculated based on the data from (a), D = dry seed. The dashed line between $24 \mathrm{DAP}$ and dry seed samples indicates further seed development after 24 DAP (Source data are shown in Supplementary Table S2) (c) Summary of ANOVA performed for (a) and (b). The sources of variance were as follows: four environment types, eight-time point (DAP), and interaction between environment and DAP. ${ }^{*}{ }^{* * *}$ Significant at $p \leq 0.05,0.001$, respectively; ns-not significant.

\subsubsection{Triploid Endosperm Tissues}

Endosperm seed tissues contained four populations of nuclei, where $3 \mathrm{C}$ and $6 \mathrm{C}$ values reflected G1 and G2 phases of the mitotic cell cycle, and 12C and 24C nuclei resulted from one and two endocycles, respectively (Supplementary Figure S3). We calculated the frequencies of individual C-values in all ten wild barley accessions up to $24 \mathrm{DAP}$, and then in dry seeds (Figure 4a; Supplementary Table S3). The inter-accession differences in endosperm C-values were striking already from the beginning of seed development. For instance, the frequency of $3 \mathrm{C}$ nuclei ranged from $50 \%$ to $80 \%$ (MHx vs. MGx, respectively), and $6 \mathrm{C}$ nuclei from $14 \%$ to $40 \%$ (inversely MGx vs. MHx, respectively) at $4 \mathrm{DAP}$. Only at this time point, all accessions contained a similar amount of endoreduplicated nuclei $(\leq 9 \%)$. From 6 to $24 \mathrm{DAP}$, the amount of $3 \mathrm{C}$ decreased approximately two times (from $\sim 60 \%$ to $\sim 25 \%$ ), the fraction of $6 \mathrm{C}$ nuclei maintained a constant level (around $\sim 30 \%$ ), and the amount of $12 \mathrm{C}$ and $24 \mathrm{C}$ nuclei continuously increased up to $50 \%$ for $\mathrm{MHx}, \mathrm{MGx}$ and WQx (all xeric accessions). In dry seeds, the fraction of $3 \mathrm{C}$ nuclei ranged from $31 \%$ to $47 \%$ (HS584 and NOm, respectively), 6C from 37\% to 57\% (NOsx vs. MHx, respectively), and endoreduplicated nuclei from $12 \%$ to $22 \%$ (NOsx vs. HS584, respectively). ANOVA results showed that the values of these variables depended on the environment type or DAP, but not the interaction between these two factors (Figure 4c).

At 4 and 6 DAP, the SCV corresponded to $\sim 0.10$. From 8 DAP, the SCV started to increase to reach the peak at 12-24 DAP. During this period, xeric accessions showed generally higher SCV. For example, it was 0.78 for MHx (16 DAP), 0.61 for MGx (16-24 DAP), and 0.66 for WQx (20 DAP). In turn, accessions from the mesic environments showed a slightly lower SCV peak, ranging from 0.47 to 0.63 for RPm (20-24 DAP) and ZFm (16 DAP), respectively. The semi-mesic BGsm and semi-xeric NOsx accessions reached the maximum SCV of 0.60 (20-24 DAP) and 0.54 (6 DAP), respectively (Figure 4b; Supplementary Table S4). ANOVA analysis revealed that the values of these variables were both environment- and DAP-, but not additively, dependent (Figure 4c). For HS584, the endosperm SCV profile was the most similar to THm and NO (Figure 4 b).

Collectively, these results demonstrated that wild barley accessions reached the peak of endosperm endoreduplication at 12-24 DAP, and endopolyploidy level tended to be higher in xeric accessions. 
(a)

END
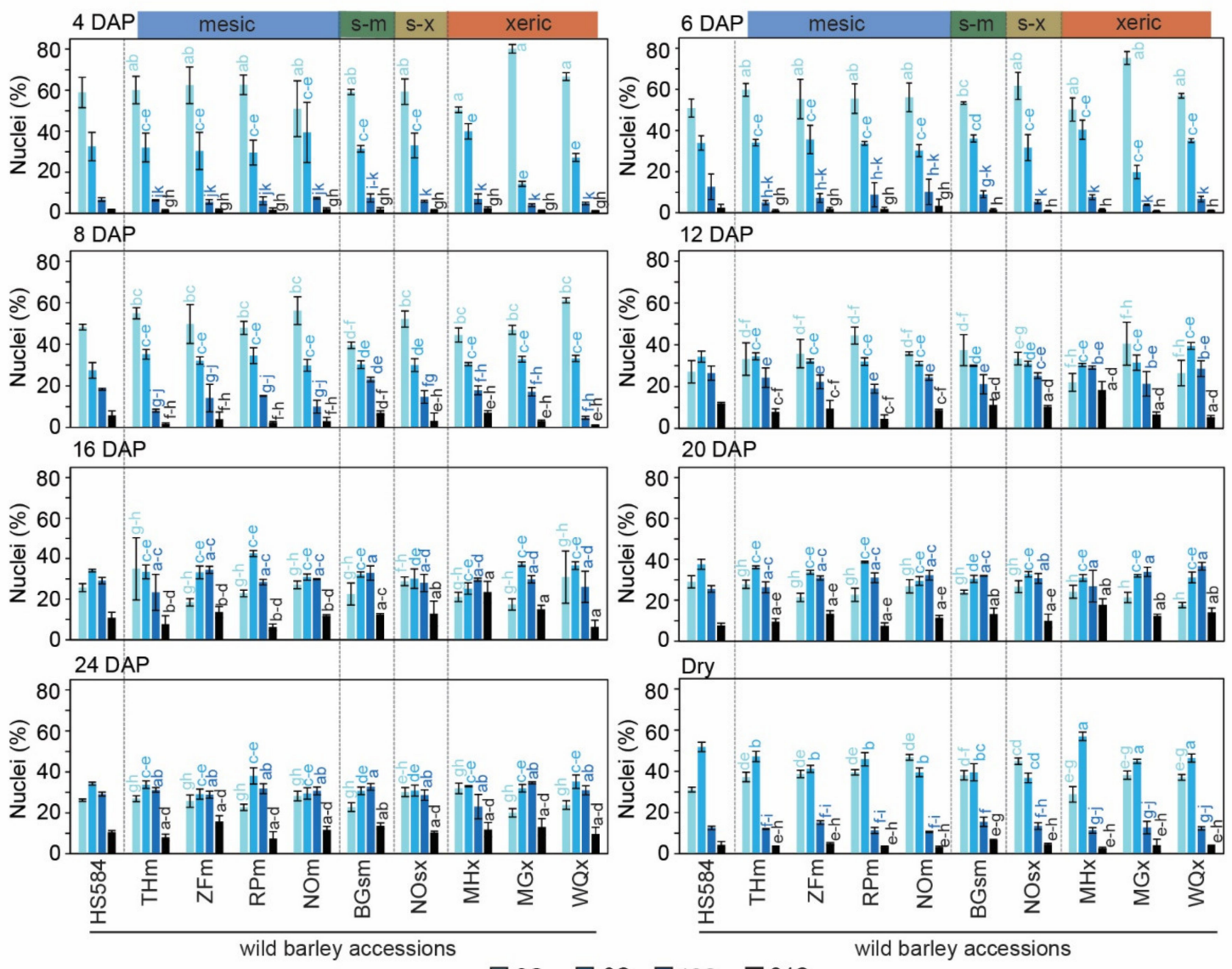

(b)

$\square 3 \mathrm{C} \quad \square 6 \mathrm{C} \square 12 \mathrm{C} \square 24 \mathrm{C}$

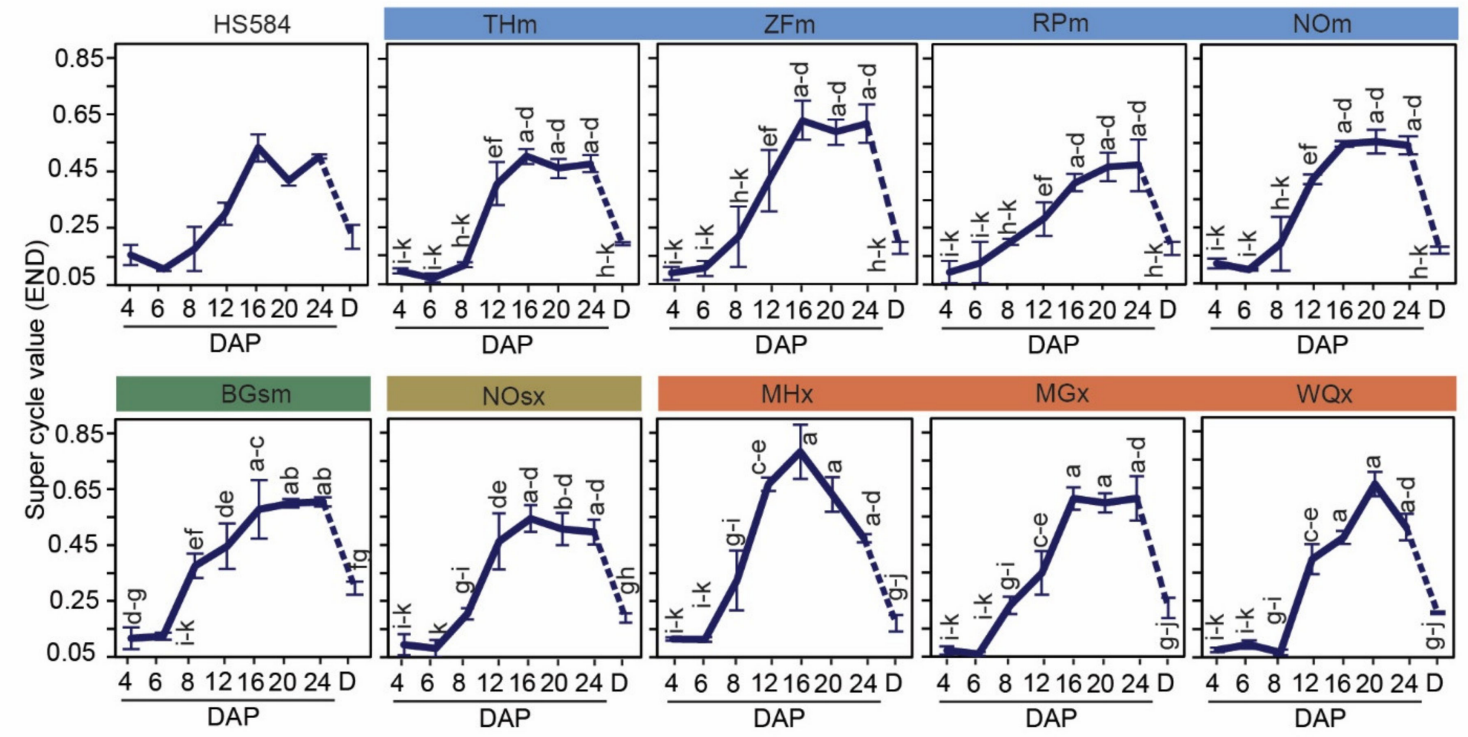

(c)

\begin{tabular}{|c|c|c|c|c|c|}
\hline Parameter & $3 \mathrm{C}(\%)$ & $6 C(\%)$ & $12 \mathrm{C}(\%)$ & $24 \mathrm{C}(\%)$ & SCV \\
\hline Source of variation & & Mean squa & & & \\
\hline Environment & $133.924 /{ }^{*}$ & $63.282 / \mathrm{ns}$ & $55.300 /{ }^{*}$ & $52.749 /{ }^{*}$ & $0.050 / * * *$ \\
\hline DAP & 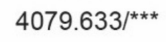 & 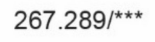 & $2018.607 /^{\star \star \star *}$ & $414.080 / * \star *$ & 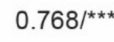 \\
\hline Environment $\times$ DAP & $69.843 / \mathrm{ns}$ & $41.299 / \mathrm{ns}$ & $20.927 / n s$ & $11.148 / \mathrm{ns}$ & $0.009 / n s$ \\
\hline
\end{tabular}

Figure 4. Estimation of $C$-values in triploid endosperm (END) tissues of ten analyzed wild barley accessions. (a) Percentage of 3C, 6C, 12C and 32C nuclei at a given day after pollination (DAP) and in dry seeds. Mesic accessions: THm $=$ Tel Hai, 
ZFm = Zefat, RPm = Rosh Pinna, NOm = Nahal Oren NSF; semi-mesic accession: BGsm = Bar Giyyora; semi-xeric accession: NOsx = Nahal Oren SFS; xeric accessions: MHx = Mehola, MGx = Machtesh Gadol, WQx = Wadi Qilt. The ecological conditions at the sampling site of HS584 are unknown. Data are the means $( \pm \mathrm{SD})$ from three biological replicates, each with at least 5 individual measurements (seeds). Data marked with the same letter do not differ according to the Duncan test $(p \leq 0.05)$ (Source data are shown in Supplementary Table S3) (b) Super cycle values at a given DAP calculated based on the data from (a), D = dry seed. The dashed line between 24 DAP and dry seed samples indicates further seed development after 24 DAP (Source data are shown in Supplementary Table S4). (c) Summary of ANOVA performed for (a) and (b). The sources of variance were as follows: four environment types, eight-time point (DAP), and interaction between environment and DAP. ${ }^{*}{ }^{* * *}$ Significant at $p \leq 0.05,0.001$, respectively; ns—not significant.

\subsection{Comparison of Endoreduplication Dynamics in Developing Seeds of Wild and Cultivated Barley}

Finding the differences between wild barley accessions, raised the question of whether it differs from cultivated barley. Therefore, we compared the data from the wild and the cultivated barley [11].

To provide a representative picture, we calculated the mean SCV at different DAP for diploid tissues (embryo and SMTs) and triploid endosperm for all ten wild barley accessions and nine barley cultivars (Figure 5a; Supplementary Table S5). The cultivars were represented by six two-rowed [11] and three six-rowed genotypes (Supplementary Figure S4). We performed ANOVA to investigate the influence of two parameters: type of the sample (wild barley vs. cultivars) and age of the seeds (Figure 5a). For diploid tissues, ANOVA revealed differences depending on DAP and on the interaction of the sample type and DAP. Both wild and cultivated barleys achieved the highest mean SCV at 12 DAP (0.32 - cultivars; 0.33 - wild barley). The mean SCV for these two types varied significantly at 4-8 DAP, 20-24 DAP and in dry seeds.

For endosperm tissues, ANOVA revealed dependency of the SCV values on the sample type and DAP, and the interactions between these two factors. Mean SCV for endosperm tissues was higher for wild barley. In wild barley, SCV peaked at 16-20 DAP reaching the value $\sim 0.55$. Cultivated barley reached a sharp peak at $16 \mathrm{DAP}$ with $\mathrm{SCV} \sim 0.46$. The mean SCV for these two types varied significantly at 16-24 DAP and in dry seeds (Figure 5a).

To gain insight into the SCV relationships among the wild and cultivated barley, we performed PC analysis (Figure 5b). The first component (PC1) grouped samples based on DAP and showed similarity between individual experimental points of diploid tissues and endosperm development. For the mix of embryo/SMT nuclei, the SCV analysis revealed two groups: (i) 4 to $8 \mathrm{DAP}$ and (ii) after 16 DAP. Similar sample distribution occurred for endosperm, excluding dry seed sample separated from the rest of time points. The second component (PC2) displayed the associations between the genotypes. The SCV data revealed two groups, the first formed by wild barley accessions and the second by barley cultivars.

Taken together, these data highlight the large inherent variation between wild and cultivated barley. Interestingly, the level of endoreduplication in endosperm tissues is higher in wild barley. 
(a)

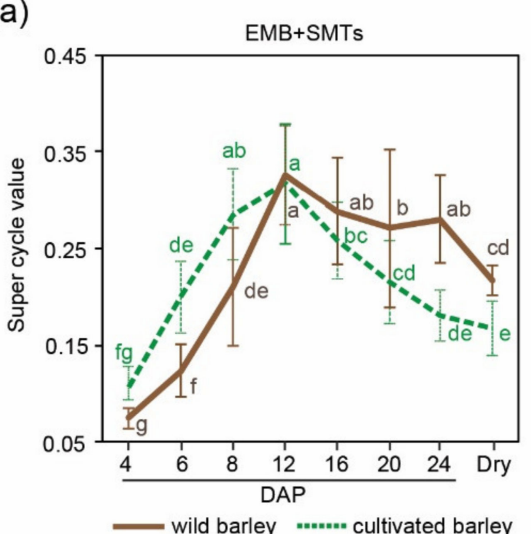

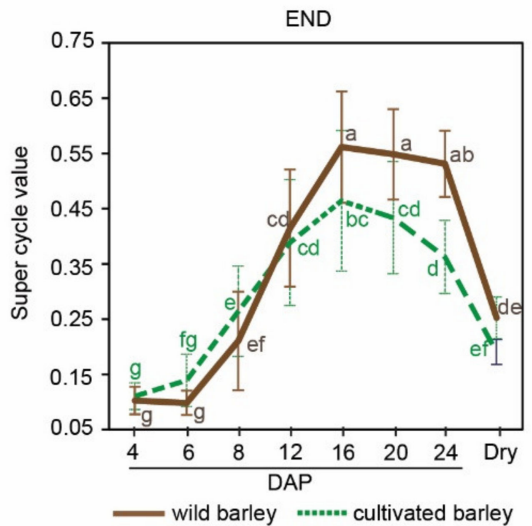

\begin{tabular}{|c|c|c|}
\hline Parameter & SCV (EMB+SMTs) & SCV (END) \\
\hline Source of variation & \multicolumn{2}{|c|}{ Mean squares $/ p$} \\
\hline Type & $0.002 / \mathrm{ns}$ & $0.060 /^{*}$ \\
\hline DAP & $0.096 / * * *$ & $0.533 /^{\star \star \star}$ \\
\hline Type $\times$ DAP & $0.019 / * \star \star *$ & $0.030 / * \star *$ \\
\hline
\end{tabular}

(b)

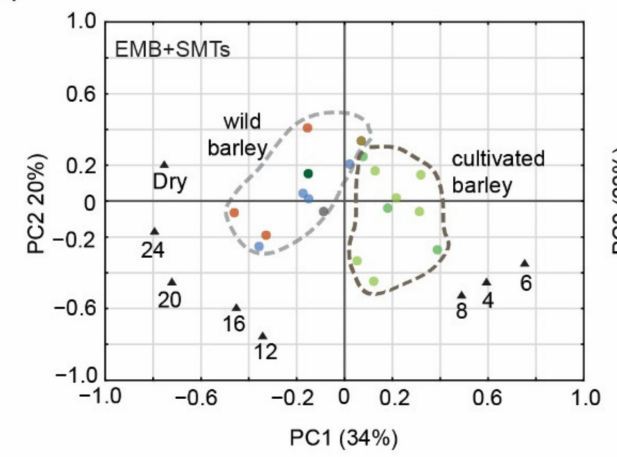

$\triangle$ DAP •HS584 •mesic •semi-mesic •semi-xeric •xeric wild barley

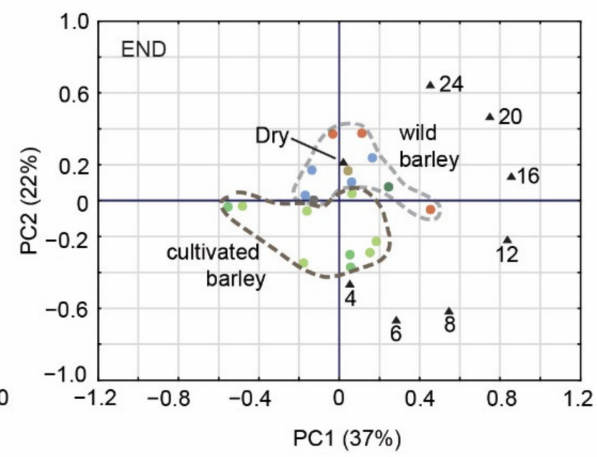

two-rowed - six-rowed

Figure 5. Comparison of the super cycle values (SCVs) for diploid seed tissues (EMB + SMTs) versus triploid endosperm (END) at given DAP between wild and cultivated barley. (a) Mean SCVs of EMB + SMTs and endosperm. Wild barley is represented by ten accessions (solid brown lines). Cultivated barley includes six two-rowed and three six-rowed cultivars (dashed green lines). Data for six-rowed cultivars are presented in Supplementary Figure S4. Data are the means $( \pm \mathrm{SD})$ from three biological replicates, each with at least 5 individual measurements (Source data are presented in Supplementary Table S5). Data marked with the same letter do not differ according to the Duncan test $(p \leq 0.05)$. The sources of variance were as follows: two types of barley (wild and cultivated), eight-time point (DAP), and interaction between type and DAP. * ${ }^{* * *}$ Significant at $p \leq 0.05,0.001$, respectively; ns-not significant. (b) Principal component (PC) analysis of SCVs in wild and cultivated barley. Numbers in the plots indicate DAP. The positions represent the contribution rates of the two main PCs to a given character. The dashed-line areas were added to highlight sample similarity.

\subsection{Morphological and Cellular Changes during 48 Days of Wild Barley Seed Development}

The need to explain the reasons for wild vs. cultivated barley endopolyploidy variation, inspired us to extend wild barley seed analysis in a broader experimental context and time. First, we monitored the dynamics of seed growth for HS584 from 4 to 48 DAP, and in dry seeds (Figure 6a; Supplementary Figure S5). At 4 DAP, SMTs constituted the dominant part of the seed. Both sagittal and transverse seed plans showed endosperm expansion, which accelerated seed growth from 6 DAP onwards (Supplementary Figure S5) and wild barley seeds reached the maximum growth (whole seed sagittal section areal $\sim 20 \mathrm{~mm}^{2}$ ) at DAP 24. Interestingly, the endosperm changed color from green to gray from DAP 32, and 
the desiccation started to be visible from DAP 40. The most intense growth of the embryo occurred around DAP 16 (Supplementary Figure S5).

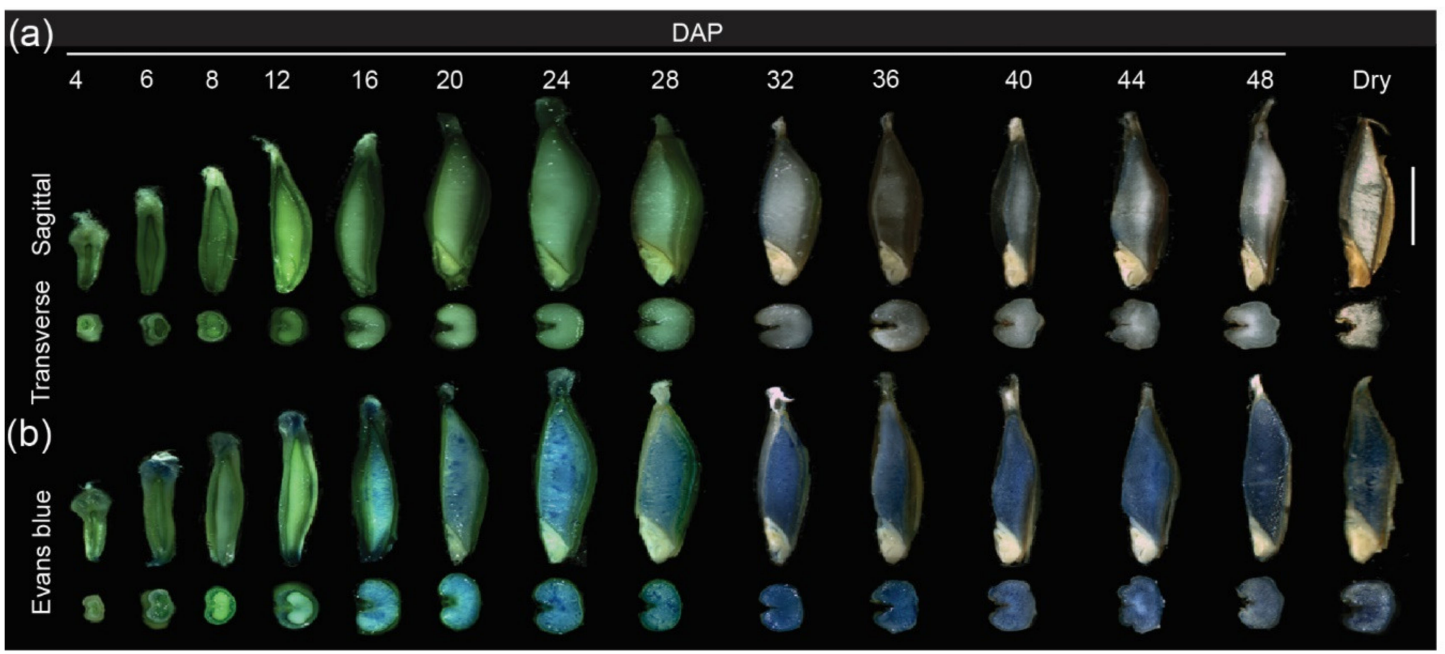

(c)
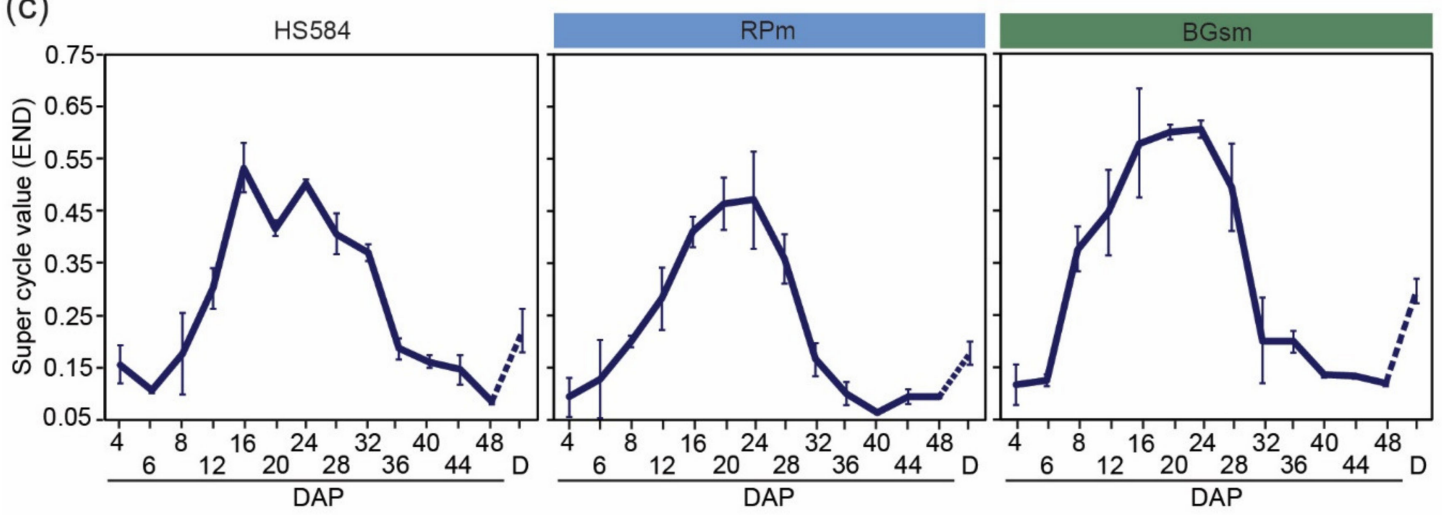

Figure 6. Time-course study of morphological and cellular events in developing wild barley seeds from 4 to 48 days after pollination (DAP). (a,b) Representative seed sections of HS584 (a) without and (b) with $0.1 \%$ Evans blue staining. The seeds shown are representative of at least 20 individuals not stained (a) and stained seed (b). Scale bar $=5 \mathrm{~mm}$. (c) Endosperm super cycle values of three wild barley accessions: HS584, Rosh Pinna and Bar Giyyora. Complementary data for diploid seed tissues are presented in Supplementary Figure S7. Data are the means $( \pm S D)$ from three biological replicates, each with at least 5 individual measurements (seeds). The dashed line between 48 DAP and dry seeds (D) samples represents the desiccation stage that was not analyzed in detail here.

Next, we analyzed cell death which is a crucial cellular process during cereal seed development. To detect viable and non-viable cells, we performed Evans blue staining (Figure $6 \mathrm{~b}$ ). The stain penetrates the intracellular spaces of dead tissues and dyes them blue. Cell death followed a specific pattern in developing wild barley seeds. We detected regions of blue staining in the top (seed brush) and bottom parts of SMTs, but not in the longitudinal elongation zone from 6 DAP onwards. In endosperm, very weak blue signals appeared in the central part at $12 \mathrm{DAP}$, and the area of staining and color intensity increased over time. AL was the only endosperm tissue free of staining at the end of seed development (Supplementary Figure S6). No staining was observed in the embryo at any stage of seed development.

Finally, we continued the measurement of nuclear C-values in seed tissues up to 48 DAP for the HS584, RPm, and BGsm accessions (Figure 6c; Supplementary Figure S7). For diploid seed tissues, the SCV profile differed between accessions. HS584 contained two peaks, at 12 and $32 \mathrm{DAP}$, reflecting probably the accumulation of endoreduplicated nuclei in SMTs and embryos, respectively. The RPm genotype had one symmetrical peak 
of endoreduplication from 6 to 28 DAP, which contrasted to very irregular peak of BGsm (Supplementary Figure S7). The SCV curve had a single broad peak profile for three studied accessions in endosperm tissues (Figure $6 c$ ). The differences concerned its width, reflecting the shifts between the start and end of the endopolyploidy period. Interestingly, the transition between low SCV at $48 \mathrm{DAP}$ and its higher value in dry seed was very clear in both diploid and triploid seed tissues.

To summarize, these results demonstrate that (i) wild barley seed reaches the accumulation of growth at 20-24 DAP; (ii) SMTs and endosperm cells undergo cell death from 6 and $12 \mathrm{DAP}$, respectively; (iii) endoreduplication is more variable in a mixture of SMTs/embryo. All our observations suggest that wild barley seed ripening and dessication continue after 48 DAP.

\section{Discussion}

Wild barley, $H$. vulgare subsp. spontaneum is abundant in diverse ecogeographic regions in the Middle East and has been studied extensively from the phenotypic, genetic, and agronomic perspectives [37-40]. Wild barley plants growing in habitats with diverse environmental conditions, are exposed to numerous stressors, which directly influence their seed yield [39]. In wild barley, spike and seed traits were expressed so far only by spike length, grain number per spike or TKW [39]. Here, we focused on the size and biomass of dry wild barley kernels. We noted that the ranges of seed traits were much wider in subsp. spontaneum than in cultivated barley [11]. Interestingly, dry seeds of wild barleys were on average longer than in the cultivars. It seems that the wild barley seed length might be an interesting trait utilized by the breeders for seed yield improvement per se. One desert genotype- $\mathrm{MHx}$ deserves special attention. It is characterized by the lowest values of all measured seed features, which might be a result of a region-specific separation [40]. As expected, the seed biomass was higher in the cultivated barley because this is the main yield-related trait used during breeding [39]. The subsp. spontaneum accessions had on average longer awns than cultivated barleys, which is in agreement with previous observation [39]. Interestingly all accessions originating from the xeric environments possessed shorter awns, which is an example of an adaptation mechanism adjusting plants to the environment [40].

Until now, advanced methods detecting morphological and cellular changes during seed development have not been used, either from a domestication or stress adaptation point of view, in wild barley. Therefore, we investigated the dynamics of endoreduplication in the diploid and triploid seed tissues from the time shortly after pollination until dry seeds. In parallel, we monitored the morphological and PCD changes accompanying endoreduplication to understand better the complexity of wild barley seed formation (Figure 7). 
(a)

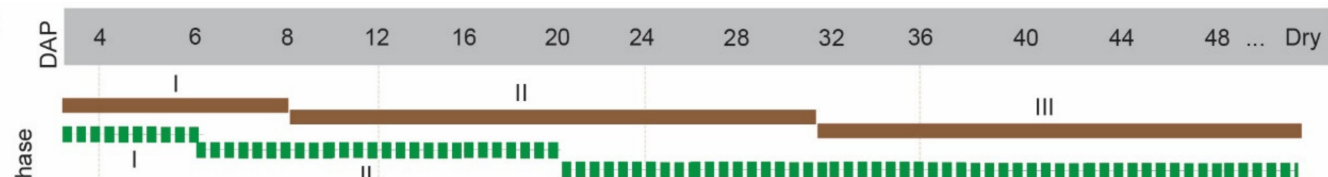

(b)

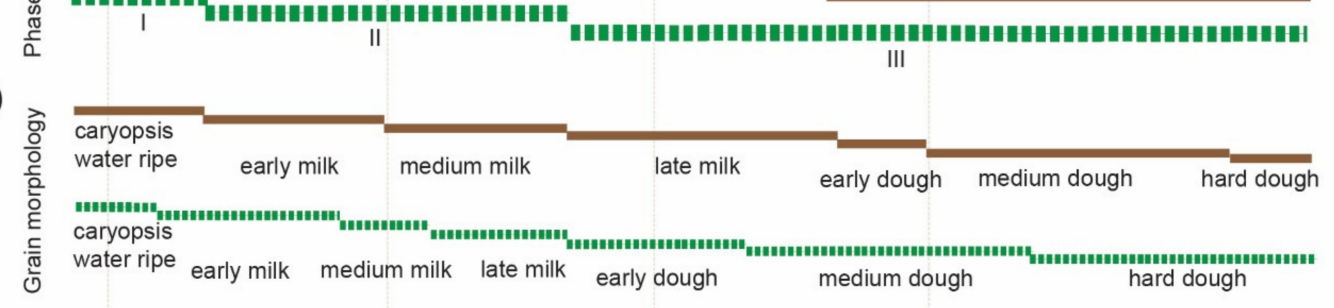

(c)

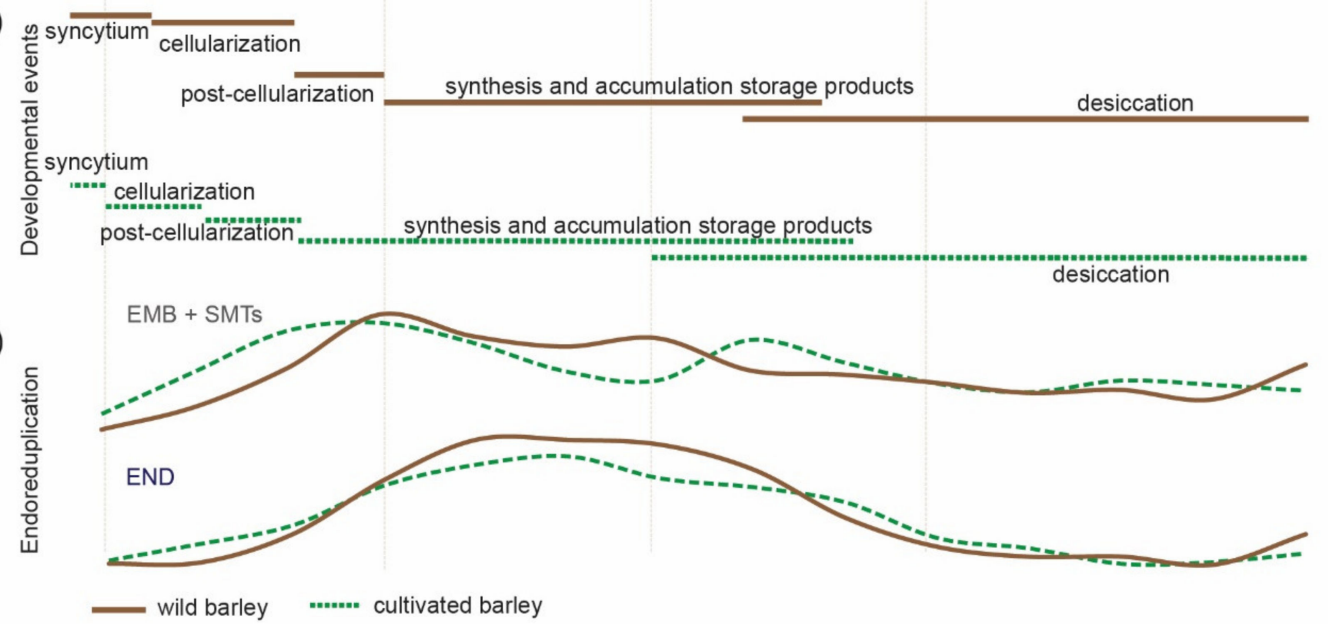

Figure 7. The model of phase transitions during wild (brown, solid lines) and cultivated barley [11] (green, dashed lines) seed development. Overview of (a) phase of barley grain development (based on [20,41], and (b) grain morphological changes (based on [12]), (c) developmental events (based on [20,41,42] and (d) endoreduplication dynamics. EMB + SMTs = embryo and seed maternal tissues and END $=$ endosperm.

There are several parameters for quantification endoreduplication level [43]. Commonly use indicator is cycle value (a.k.a. endoreduplication index) [44]. However, this formula considers $4 \mathrm{C}$ (and $6 \mathrm{C}$ endosperm) nuclei as already endoreduplicated. Although some $4 \mathrm{C}$ nuclei (6C) might already be programmed for endoreduplication, others will be regularly cycling G2 nuclei. FCM does not recognize which 4C nuclei will undergo the mitotic cell cycle and which endocycle. Therefore, we recently introduced a new conservative formula, which considers that $8 \mathrm{C}$ nuclei (and $12 \mathrm{C}$ nuclei in endosperm) as the first unambiguous level of endoreduplication [11].

Many dicots possess non-endospermic seeds, where the developing embryo consumes most of the endosperm before the seed maturation. For the non-endospermic seeds, endoreduplication intensity is a marker of seed quality and maturation [36,45]. In contrast, grasses (Poaceae) have endospermic seeds which means that the endosperm forms the major and embryo the minor tissue mass of the fully developed seed. Besides, the high nutritional value of endosperm makes cereals the main crops worldwide to produce energy for humans and livestock. Endoreduplication appears during endosperm development and is correlated with the rapid growth of the caryopsis, the synthesis and accumulation of storage compounds, mainly starch and proteins in cereals [20]. We found that during seed development, both wild and cultivated barley endosperm underwent two rounds of endoreduplication resulting in $12 \mathrm{C}$ and $24 \mathrm{C}$ nuclei, respectively [11]. Two endocycles also appeared during wheat [46] and rice [47] endosperm development. Four and up to seven rounds of endoreduplication were found in the endosperm of sorghum [48] and maize [49], respectively. This suggests that the upper level of endopolyploidization is genetically regulated in the cereal endoserm, including $H$. vulgare. Further genetic 
variation most likely exists in the kinetics of endoreduplication which is suggested by the different SCV profiles observed in our study for different genotypes when grown under identical cultivation conditions. In wild barley, the major endoreduplication activity started $\sim 8 \mathrm{DAP}$, i.e., two days later compared to the cultivated barley [11]. In both taxa, the SCV decreased after 32 DAP. The study performed in cultivated barley has already shown that endosperm endoreduplication nuclei were progressively degraded during the accumulation of the storage materials and ripening. This degeneration was initiated in highly endopolyploid nuclei and accompanied by accumulation of DNA damage and cell death [11]. Interestingly, we detected high proportion of endoreduplicated nuclei in dry seeds for subsp. spontaneum. Admittedly, desiccating and dry seeds of cultivated barley also contained endoreduplicated nuclei [11], but not in such proportion as in wild barley. Microscopic observations confirmed that endoreduplicated nuclei originated from AL in dry barley seeds [50]. Endoreduplicated AL nuclei are not observed in other cereals except for barley [50].

Here, we also found that wild barley has shifted the major seed/endosperm morphological and developmental phases and needs more time to complete seed ripening comparing to cultivated barley (Figure 6a-c) [11]. Delayed desiccation period and entrance into dough phases were the most obvious differences between wild and cultivated strains [12]. Our findings complement previous observations of several days difference in the heading and anthesis in wild versus cultivated barley [39]. Furthermore, the gray color of maturating endosperm in subsp. spontaneum, comparing to the white-yellow color of endosperm in cultivated barley [11], may reflect distinct compositions of storage compounds. So far, transcriptomic and metabolomic profiles of seed storage compounds are available for cultivated but not for wild barley [51]. The darker color of wild barley endosperm may also indicate the presence of secondary metabolites, e.g., anthocyanins or other reactive oxygen species scavenging molecules [52,53]. Taken together, all results collected for wild and cultivated barleys raised the question whether there is a link between higher endoreduplication level and different color of endosperm in wild barley. However, solving this question will require further studies, for example examination of the secondary metabolites using high-performance liquid chromatography. Extended analysis may help to better understand the mechanisms of stress adaptation and cereal seed improvement.

Based on the studies in cultivated barley, we concluded that endoreduplication in SMTs is correlated with starch deposition, and in embryos with differentiation of the tissues [11]. We detected two populations of endopolyploid nuclei (8C and 16C reflecting one and two endocycles, respectively) in a mixture of diploid seed tissues of wild barley which is similar to cultivated barley [11]. This is additional evidence suggesting that the number of endocycles is genetically controlled and species-specific [54]. We noted that in the mixture of SMTs/embryo of subsp. spontaneum seeds, that endoreduplication peaked two times at 12 and 24 DAP. Comparing wild and cultivated barley, the level of endoreplication expressed by SCV was the same, however, the peaks were shifted. We assign the first endoreduplication peak to SMTs, which correlates with their intensive growth. We assume that the second endoreduplication peak should be attributed to the embryo, and correlate with its rapid growth and tissue differentiation. Similarly to the endosperm, wild barley dry seed tissues contained higher proportion of endoreduplicated nuclei as compared to 48 DAP sample. However, this observation was exclusive only for wild, not cultivated barley (Figure 6). Among ten wild barley accessions, we found variation in the dynamics of SMTs/embryo and endosperm endopolyploidization. On the one hand, some accessions had shifted in time the endoreduplication peak, on the other hand, there were differences with SCV throughout the entire seed development. This finding unravels a new level of variation between wild barley populations. However, it has to be noted that the accessions used in our report represent only a limited diversity and that the variation is probably much greater in wild barley. Intra-specific endpolyoploidy variation is quite common in both cultivated $[39,40]$ and wild [55] plants. Studies performed 
in Arabidopsis revealed that endoreduplication levels are controlled by the interaction of multiple mostly cell cycle-related genes [55].

Importantly, we detected a link between the amount of endoreduplicated nuclei and the ecogeographical origin of the wild barley accessions. Namely, accessions originating from the xeric environments tended to have higher SCV for both SMTs/embryo and endosperm tissues. This is analogous with the previous findings for Israeli accessions of wild barley, in the context of genetic variability detected by molecular markers [56]. Many studies have found endoreduplication more abundantly among plants that grow under environmentally challenging conditions $[21,22,27,57]$. Increasing DNA content may be integrated into the damage-induced oxidative stress-response systems, like for instance pentose phosphate pathway [58]. In this system, endoreduplication may promote compensation to damages by upregulation of gene expression involved in the overproduction of metabolites [58]. On the other hand, endopolyploidy is thought to play significant roles in plant physiology [21]. Altered phytohormone balances, changed after exposition to environmental stressors, probably trigger organ-specific endopolyploidization [24]. This may suggest an adaptive mechanism to an environmental gradient that results in differential endopolyploidy [24]. With only ten accessions used in this study, the identification of an obvious adaptive response to harsh environmental conditions is not conclusive. Therefore, to identify a potential link between environmental gradient and seed endoreduplication variation, future studies involving a larger number of genetically defined samples and mapping causal genes are necessary.

\section{Conclusions and Future Perspectives}

Both diploid and triploid barley seed tissues undergo two endocycles. This study of endoreduplication in wild barley seeds revealed a new level of variation appearing within subsp. spontaneum. Wild barley had a higher endoreduplication level in endosperm tissues comparing with the with cultivated one and the amount of endoreduplicated nuclei tended to be higher in xeric accessions. We are currently aiming to better understand how spatiotemporal seed endoreduplication patterns change under various stresses and whether these stresses are linked to stress adaptation.

Supplementary Materials: The following are available online at https:/ /www.mdpi.com/article/ 10.3390/genes12050711/s1, Figure S1: Phenotypic analysis of dry seeds of wild barley accessions originating from Israel; Figure S2: Principal component (PC) analysis of TKW, seed length and width for peeled seeds, and awn length; Figure S3: An example showing the interpretation of histograms of nuclear DNA content; Figure S4: Comparison of super cycle values in seed tissues of three six-rowed barley cultivars; Figure S5: Time-course study of wild barley HS584 seed growth; Figure S6: Analysis the aleurone layer viability; Figure S7: Comparison of super cycle values in diploid seed tissues of three selected wild barley accessions at given DAP; Table S1: Percentage of 2C, 4C, 8C and 16C nuclei at a given DAP and in dry seeds in diploid seed tissues; Table S2: Super cycle values at a given DAP calculated for SMTs; Table S3. Percentage of 3C, 6C, 12C and 24C nuclei at a given DAP and in dry seeds in endosperm; Table S4: Super cycle values at a given DAP calculated for endosperm; Table S5: Super cycle values at a given DAP calculated for embryo/seed maternal tissues and endosperm.

Author Contributions: Conceptualization, A.P., A.N. and T.K.; methodology, A.N.; software, A.N. and P.P.S.; validation, A.N. and P.P.S.; formal analysis, A.N. and A.P.; investigation, A.N., P.P.S., M.K., D.W. and B.T.; resources, T.K.; data curation, A.N. and P.P.S.; writing-original draft preparation, A.N. and P.P.S.; writing—review and editing, A.P.; visualization, A.N.; supervision, A.P.; project administration, A.P.; funding acquisition, A.P. All authors have read and agreed to the published version of the manuscript.

Funding: This research was funded by the Czech Science Foundation, grants numbers 18-12197S (A.P.) and 21-02929S (A.P.) and 20-25845Y (P.P.S.), Purkyně Fellowship from the Czech Academy of Sciences to A.P., and the ERDF project "Plants as a tool for sustainable global development" (No. CZ.02.1.01/0.0/0.0/16_019/0000827). Also, we thank COST action 16212 Impact of Nuclear Domains On Gene Expression and Plant Traits (INDEPTH) for creating the ground for developing this project and supporting meetings of the authors during its realization. 
Institutional Review Board Statement: Not applicable.

Informed Consent Statement: Not applicable.

Data Availability Statement: Not applicable.

Acknowledgments: We thank Marion Röder (Leibniz Institute of Plant Genetics and Crop Plant Research (IPK) in Germany) for providing seeds of H. vulgare subsp. spontaneum HS584, Petr Capal for the maintenance of flow cytometers, Sariel Hubner for the photo of xeric site barley, Eva Jahnová and Suad Chalifa for technical assistance, and Zdenka Bursová for plant care.

Conflicts of Interest: The authors declare no conflict of interest. The funders had no role in the design of the study; in the collection, analyses, or interpretation of data; in the writing of the manuscript, or in the decision to publish the results.

\section{References}

1. Badr, A.; Müller, K.; Schäfer-Pregl, R.; El Rabey, H.; Effgen, S.; Ibrahim, H.H.; Pozzi, C.; Rohde, W.; Salamini, F. On the origin and domestication history of barley (Hordeum vulgare). Mol. Biol. Evol. 2000, 17, 499-510. [CrossRef]

2. Mascher, M.; Schuenemann, V.J.; Davidovich, U.; Marom, N.; Himmelbach, A.; Hübner, S.; Korol, A.; David, M.; Reiter, E.; Riehl, S.; et al. Genomic analysis of 6,000-year-old cultivated grain illuminates the domestication history of barley. Nat. Genet. 2016, 48, 1089-1093. [CrossRef] [PubMed]

3. Jakob, S.S.; Rödder, D.; Engler, J.O.; Shaaf, S.; Özkan, H.; Blattner, F.R.; Kilian, B. Evolutionary history of wild barley (Hordeum vulgare subsp. spontaneum) analyzed using multilocus sequence data and paleodistribution modeling. Genome Biol. Evol. 2014, 6, 685-702. [CrossRef] [PubMed]

4. Krugman, T.; Nevo, E.; Beharav, A.; Sela, H.; Fahima, T. The Institute of Evolution Wild Cereal Gene Bank at the University of Haifa. Isr. J. Plant. Sci. 2019, 65, 129-146. [CrossRef]

5. Von Korff, M.; Wang, H.; Léon, J.; Pillen, K. Development of candidate introgression lines using an exotic barley accession (Hordeum vulgare ssp. spontaneum) as donor. Theor. Appl. Genet. 2004, 109, 1736-1745. [CrossRef]

6. Nevo, E. Origin, evolution, population genetics and resources for breeding of wild barley, Hordeum spontaneum, in the Fertile Crescent. In Barley: Genetics, Biochemistry, Molecular Biology and Biotechnology; Shewry, P., Ed.; Centre for Agriculture and Bioscience International: Wallingford, UK, 1992; pp. 19-43. ISBN 0-85198-725-7.

7. Fetch, T.G.; Steffenson, B.J.; Nevo, E. Diversity and sources of multiple disease resistance in Hordeum spontaneum. Plant. Dis. 2003, 87, 1439-1448. [CrossRef]

8. Grossi, M.; Giorni, E.; Rizza, F.; Stanca, A.M.; Cattivelli, L. Wild and cultivated barleys show differences in the expression pattern of a cold-regulated gene family under different light and temperature conditions. Plant. Mol. Biol. 1998, 38, 1061-1069. [CrossRef] [PubMed]

9. Cai, K.; Chen, X.; Han, Z.; Wu, X.; Zhang, S.; Li, Q.; Nazir, M.M.; Zhang, G.; Zeng, F. Screening of worldwide barley collection for drought tolerance: The assessment of various physiological measures as the selection criteria. Front. Plant. Sci. 2020, 11, 1159. [CrossRef]

10. Nevo, E.; Krugman, T.; Beiles, A. Genetic resources for salt tolerance in the wild progenitors of wheat (Triticum dicoccoides) and barley (Hordeum spontaneum) in Israel. Plant. Breed. 1993, 110, 338-341. [CrossRef]

11. Nowicka, A.; Kovacik, M.; Tokarz, B.; Vrána, J.; Zhang, Y.; Weigt, D.; Doležel, J.; Pecinka, A. Dynamics of endoreduplication in developing barley seeds. J. Exp. Bot. 2021, 72, 268-282. [CrossRef]

12. Tottman, D.R.; Makepeace, R.J.; Broad, H. An explanation of the decimal code for the growth stages of cereals, with illustrations. Ann. Appl. Biol. 1979, 93, 221-234. [CrossRef]

13. Evers, T.; Millar, S. Cereal grain structure and development: Some implications for quality. J. Cereal Sci. 2002, 36, 261-284. [CrossRef]

14. Radchuk, V.; Borisjuk, L. Physical, metabolic and developmental functions of the seed coat. Front. Plant. Sci. 2014, 5, 510. [CrossRef]

15. Evers, A.D.; Blakeney, A.; O’Brien, L. Cereal structure and composition. Aust. J. Agric. Res. 1999, 50, 629-650. [CrossRef]

16. Olsen, O.-A. Endosperm development: Cellularization and cell fate specification. Annu. Rev. Plant. Physiol. Plant. Mol. Biol. 2001, 52, 233-267. [CrossRef]

17. Rodríguez, M.V.; Barrero, J.M.; Corbineau, F.; Gubler, F.; Benech-Arnold, R.L. Dormancy in cereals (not too much, not so little): About the mechanisms behind this trait. Seed Sci. Res. 2015, 25, 99-119. [CrossRef]

18. D'amato, F. Endopolyploidy as a factor in plant tissue development. Caryologia 1964, 17, 41-52. [CrossRef]

19. Nagl, W. DNA endoreduplication and polyteny understood as evolutionary strategies. Nature 1976, 261, 614-615. [CrossRef]

20. Sabelli, P.A.; Larkins, B.A. The development of endosperm in grasses. Plant. Physiol. 2009, 149, 14-26. [CrossRef]

21. De Veylder, L.; Larkin, J.C.; Schnittger, A. Molecular control and function of endoreplication in development and physiology. Trends Plant. Sci. 2011, 16, 624-634. [CrossRef]

22. Scholes, D.R.; Paige, K.N. Plasticity in ploidy: A generalized response to stress. Trends Plant. Sci. 2015, 20, 165-175. [CrossRef] 
23. Gendreau, E.; Traas, J.; Desnos, T.; Grandjean, O.; Caboche, M.; Hofte, H. Cellular basis of hypocotyl growth in Arabidopsis thaliana. Plant. Physiol. 1997, 114, 295-305. [CrossRef]

24. Bhosale, R.; Boudolf, V.; Cuevas, F.; Lu, R.; Eekhout, T.; Hu, Z.; Van Isterdael, G.; Lambert, G.M.; Xu, F.; Nowack, M.K.; et al. A spatiotemporal dna endoploidy map of the Arabidopsis root reveals roles for the endocycle in root development and stress adaptation. Plant. Cell 2018, 30, 2330-2351. [CrossRef]

25. Lingua, G.; Fusconi, A.; Berta, G. The nucleus of differentiated root plant cells: Modifications induced by arbuscular mycorrhizal fungi. Eur. J. Histochem. 2001, 45, 9-20. [CrossRef]

26. Chandran, D.; Inada, N.; Hather, G.; Kleindt, C.K.; Wildermuth, M.C. Laser microdissection of Arabidopsis cells at the powdery mildew infection site reveals site-specific processes and regulators. Proc. Natl. Acad. Sci. USA 2010, 107, 460-465. [CrossRef] [PubMed]

27. Cookson, S.J.; Radziejwoski, A.; Granier, C. Cell and leaf size plasticity in Arabidopsis: What is the role of endoreduplication? Plant. Cell Environ. 2006, 29, 1273-1283. [CrossRef] [PubMed]

28. Tran, V.; Weier, D.; Radchuk, R.; Thiel, J.; Radchuk, V. Caspase-like activities accompany programmed cell death events in developing barley grains. PLoS ONE 2014, 9, e109426. [CrossRef] [PubMed]

29. Radchuk, V.; Tran, V.; Radchuk, R.; Diaz-Mendoza, M.; Weier, D.; Fuchs, J.; Riewe, D.; Hensel, G.; Kumlehn, J.; Munz, E.; et al. Vacuolar processing enzyme 4 contributes to maternal control of grain size in barley by executing programmed cell death in the pericarp. New Phytol. 2018, 218, 1127-1142. [CrossRef] [PubMed]

30. Young, T.E.; Gallie, D.R. Programmed cell death during endosperm development. Plant. Mol. Biol. 2000, 44, 283-301. [CrossRef] [PubMed]

31. Wu, X.; Liu, J.; Li, D.; Liu, C.M. Rice caryopsis development II: Dynamic changes in the endosperm. J. Integr. Plant. Biol. 2016, 58, 786-798. [CrossRef]

32. Nevo, E. Evolution of wild barley at "Evolution Canyon": Adaptation, speciation, pre-agricultural collection, and barley improvement. Isr. J. Plant. Sci. 2015, 62, 22-32. [CrossRef]

33. Waddington, S.R.; Cartwright, P.M.; Wall, P.C. A quantitative scale of spike initial and pistil development in barley and wheat. Ann. Bot. 1983, 51, 119-130. [CrossRef]

34. Kovacik, M.; Nowicka, A.; Pecinka, A. Isolation of high purity tissues from developing barley seeds. J. Vis. Exp. 2020, 1-2. [CrossRef] [PubMed]

35. Nevo, E.; Zohary, D.; Brown, A.H.D.; Haber, M. Genetic diversity and environmental associations of wild barley, Hordeum spontaneum, in Israel. Evolution 1979, 33, 815-833. [CrossRef]

36. Rewers, M.; Sliwinska, E. Endoreduplication intensity as a marker of seed developmental stage in the Fabaceae. Cytom. Part $A$ 2012, 81A, 1067-1075. [CrossRef]

37. Nevo, E.; Beiles, A.; Kaplan, D.; Storch, N.; Zohary, D. Genetic diversity and environmental associations of wild barley, Hordeum spontaneum (Poaceae), in Iran. Plant. Syst. Evol. 1986, 153, 141-164. [CrossRef]

38. Hosseini, M.; Ghorbani, R.; Rashed Mohassel, M.H.; Yassaie, M. Correlation of environmental factors and phenotypic diversity of iranian wild barley (Hordeum Spontaneum Koch) populations. Acta Oecologica 2019, 95, 19-25. [CrossRef]

39. Shakhatreh, Y.; Haddad, N.; Alrababah, M.; Grando, S.; Ceccarelli, S. Phenotypic diversity in wild barley (Hordeum vulgare L. ssp. spontaneum (C. Koch) Thell.) accessions collected in Jordan. Genet. Resour. Crop. Evol. 2010, 57, 131-146. [CrossRef]

40. Volis, S.; Mendlinger, S.; Ward, D. Adaptive traits of wild barley plants of Mediterranean and desert origin. Oecologia 2002, 133, 131-138. [CrossRef]

41. Dante, R.A.; Larkins, B.A.; Sabelli, P.A. Cell cycle control and seed development. Front. Plant. Sci. 2014, 5, 493. [CrossRef]

42. Sreenivasulu, N.; Borisjuk, L.; Junker, B.H.; Mock, H.-P.; Rolletschek, H.; Seiffert, U.; Weschke, W.; Wobus, U. Barley grain development: Toward an integrative view. In International Review of Cell and Molecular Biology; Jeon, K., Ed.; Elsevier: Amsterdam, The Netherlands, 2010; Volume 281, pp. 49-89.

43. Rewers, M.; Sadowski, J.; Sliwinska, E. Endoreduplication in cucumber (Cucumis sativus) seeds during development, after processing and storage, and during germination. Ann. Appl. Biol. 2009, 155, 431-438. [CrossRef]

44. Barow, M.; Meister, A. Endopolyploidy in seed plants is differently correlated to systematics, organ, life strategy and genome size. Plant. Cell Environ. 2003, 26, 571-584. [CrossRef]

45. Sliwinska, E.; Lukaszewska, E. Polysomaty in growing in vitro sugar-beet (Beta vulgaris L.) seedlings of different ploidy level. Plant. Sci. 2005, 168, 1067-1074. [CrossRef]

46. Chojecki, A.; Gale, M.; Bayliss, M. The number and sizes of starch granules in the wheat endosperm, and their association with grain weight. Ann. Bot. 1986, 58, 819-831. [CrossRef]

47. Kobayashi, H. Variations of endoreduplication and its potential contribution to endosperm development in rice (Oryza sativa L.). Plant. Prod. Sci. 2019, 22, 227-241. [CrossRef]

48. Kladnik, A.; Chourey, P.S.; Pring, D.R.; Dermastia, M. Development of the endosperm of Sorghum bicolor during the endoreduplication-associated growth phase. J. Cereal Sci. 2006, 43, 209-215. [CrossRef]

49. Sabelli, P.A.; Larkins, B.A. Regulation and function of retinoblastoma-related plant genes. Plant. Sci. 2009, 177, 540-548. [CrossRef]

50. Keown, A.C.; Taiz, L.; Jones, R.L. The nuclear DNA content of developing barley aleurone cells. Am. J. Bot. 1977, 64, 1248-1253. [CrossRef] 
51. Sreenivasulu, N.; Usadel, B.; Winter, A.; Radchuk, V.; Scholz, U.; Stein, N.; Weschke, W.; Strickert, M.; Close, T.J.; Stitt, M.; et al. Barley grain maturation and germination: Metabolic pathway and regulatory network commonalities and differences highlighted by new MapMan/PageMan profiling tools. Plant. Physiol. 2008, 146, 1738-1758. [CrossRef]

52. Burešová, V.; Kopecký, D.; Bartoš, J.; Martinek, P.; Watanabe, N.; Vyhnánek, T.; Doležel, J. Variation in genome composition of blue-aleurone wheat. Theor. Appl. Genet. 2015, 128, 273-282. [CrossRef]

53. Jeewani, D.C.; Hua, W.Z. Grain color development and segregation of blue wheat. Res. J. Biotechnol. 2017, 12, 40-45.

54. Chevalier, C.; Nafati, M.; Mathieu-Rivet, E.; Bourdon, M.; Frangne, N.; Cheniclet, C.; Renaudin, J.P.; Gvaudant, F.; Hernould, M. Elucidating the functional role of endoreduplication in tomato fruit development. Ann. Bot. 2011, 107, 1159-1169. [CrossRef] [PubMed]

55. Sterken, R.; Kiekens, R.; Boruc, J.; Zhang, F.; Vercauteren, A.; Vercauteren, I.; De Smet, L.; Dhondt, S.; Inzé, D.; De Veylder, L.; et al. Combined linkage and association mapping reveals CYCD5;1 as a quantitative trait gene for endoreduplication in Arabidopsis. Proc. Natl. Acad. Sci. USA 2012, 109, 4678-4683. [CrossRef]

56. Hübner, S.; Höffken, M.; Oren, E.; Haseneyer, G.; Stein, N.; Graner, A.; Schmid, K.; Fridman, E. Strong correlation of wild barley (Hordeum spontaneum) population structure with temperature and precipitation variation. Mol. Ecol. 2009, 18, 1523-1536. [CrossRef]

57. Barow, M. Endopolyploidy in seed plants. BioEssays 2006, 28, 271-281. [CrossRef]

58. Siddappaji, M.H.; Scholes, D.R.; Bohn, M.; Paige, K.N. Overcompensation in response to herbivory in Arabidopsis thaliana: The role of glucose-6-phosphate dehydrogenase and the oxidative pentose-phosphate pathway. Genetics 2013, 195, 589-598. [CrossRef] 